\title{
Inmigración y emigración en Colonia Caesar Augusta (siglos I-II d.C.)
}

\author{
Immigration and emigration \\ in Colonia Caesar Augusta \\ $\left(1^{s t}-2^{\text {nd }}\right.$ centuries $\left.A D\right)$
}

\author{
José Ortiz Córdoba \\ Universidad de Granada \\ joseortiz@ugr.es
}

Resumen: Este trabajo tiene como principal objetivo estudiar las dinámicas de movilidad existentes entre los habitantes de Caesar Augusta. La base fundamental del estudio está constituida por la documentación epigráfica relacionada con dicha colonia. El análisis de los distintos tipos de movilidad existentes y de las causas que motivaron los desplazamientos conforman los ejes fundamentales de esta contribución.

Palabras clave: Inmigración. Emigración. Movilidad. Caesar Augusta. Epigrafía latina

Abstract: The objective of this paper is to study the dynamics of mobility among the inhabitants of Caesar Augusta. The basis of the study is constituted by the epigraphic documentation related to this colony. The analysis of the different types of mobility and of the causes that motivated the displacements are the main axes of this contribution.

Key words: Immigration. Emigration. Mobility. Caesar Augusta. Latin Epigraphy.

Recepción: 02.07.2019 | Aceptación: 05.09.2019

Proyectos: Este trabajo se inscribe dentro de las líneas de investigación del grupo HUM-215 dirigido por C. González Román y ha sido realizado gracias a la concesión del proyecto de investigación Veterani et milites en las colonias romanas de Hispania, financiado por la Universidad de Granada en el marco del Programa de Proyectos de Investigación para Jóvenes Investigadores. 


\section{Introducción}

Son muchos los trabajos relacionados con los movimientos de población que durante las últimas décadas han visto la luz. ${ }^{1}$ Todos ellos han subrayado y puesto de manifiesto la enorme diversidad y complejidad de los mismos. En el caso hispano la revisión de la documentación literaria y la continua actualización de la epigrafía nos han permitido constatar la existencia de numerosos movimientos de población que remiten sobre todo a época romana. Éstos tuvieron en sus inicios un carácter fundamentalmente inmigratorio y acompañaron al proceso de conquista, que favoreció la llegada de un notable volumen de población itálica cuyo asentamiento en la Península Ibérica fue determinante para impulsar el proceso de romanización. Esta corriente migratoria alcanzó su máximo desarrollo durante la colonización cesariana y augustea, momento en que fueron asentados en Hispania numerosos contingentes de población derivados en buena medida de la desmovilización del ejército romano tras las guerras civiles. Su trascendencia fue subrayada por los propios autores del momento. Concretamente, Suetonio alude a las 80.000 personas que fueron establecidas por César en territorio provincial (Suet., Caes. 42, 1), mientras que el propio Augusto, en sus Res Gestae, habla de los 300.000 veteranos que procedió a instalar en diversas colonias creadas en Italia y las provincias. Con posterioridad, la plena integración de Hispania en el mundo romano favoreció el desarrollo de movimientos de población en sentido contrario. Mediante los mismos el elemento hispano se proyectó fuera de la Península Ibérica por causas militares, económicas y administrativas. ${ }^{2}$ Asimismo, la notable red urbana establecida por Roma favoreció los desplazamientos intrapeninsulares, que tuvieron en las capitales provinciales y en las colonias costeras sus principales centros de referencia.

Este trabajo tiene como objetivo el estudio de algunas de las dinámicas de movilidad anteriormente referidas en relación a la colonia de Caesar Augusta, una de las principales ciudades de la Hispania Citerior. Esta enorme provincia presentaba importantes diferencias entre las tierras costeras y el valle del Ebro, donde la vida urbana era intensa y el desarrollo económico mayor, y las regiones del interior, que apenas contaban con grandes ciudades y cuyos recursos,

1 A modo de ejemplo: Haley 1986; Marín 1988; Haley 1991; Marco, Pina y Remesal 2004; Caballos y Demougin 2006; Iglesias y Ruiz 2011; De Ligt y Tacoma 2016; Ortiz 2019a.

2 Cf. García 1991, 263-302; 1994a, 383-390; 1994b, 457-462; Ricci 1992, 103-143; Ortiz 2017, 135-158; 2018, 83-116; 2019c, 459-488. 
si exceptuamos la riqueza minera del noroeste, eran exiguos. Este fuerte contraste debe relacionarse con la propia evolución histórica del territorio, donde la colonización romana se concentró principalmente en su zona costera; en ella encontramos algunos de los principales centros urbanos de la Península Ibérica, como Tarraco, Barcino o Carthago Nova. Por el contrario, este proceso estuvo prácticamente ausente en las tierras del interior, con la única excepción de los distritos mineros del sur, donde fueron emplazadas Libisosa y Salaria, y del Valle del Ebro, donde las colonias de Celsa y Caesar Augusta controlaban este paso estratégico hacia el interior de la Península. A ello debemos unir la tardía incorporación de los territorios del norte y noroeste peninsular, cuya adaptación al mundo romano se produjo desde parámetros diferentes. Esta gran diversidad favoreció el desarrollo de especificidades propias en el campo de la administración. En ella los conventus iuridici jugaron un papel clave como elemento vertebrador de la provincia, sobre todo en las regiones del centro y el noroeste. ${ }^{3}$ Esta circunstancia afectó también al desarrollo de sus respectivas capitales, convertidas a partir de este momento en centro de referencia para las élites locales de su entorno inmediato. Este será el caso de Caesar Augusta, que a su papel como capital conventual unía su estratégica posición en el curso medio del Ebro, actuando de esta manera como puente entre la costa y el interior de la provincia.

Para el estudio de las dinámicas de movilidad existentes entre los habitantes de Caesar Augusta hemos procedido a la revisión de los distintos corpora provinciales hispanos y de las diversas bases de datos informáticas existentes sobre la epigrafía latina de la Península Ibérica y de las provincias del Imperio. Los criterios empleados para detectar la llegada de población foránea a Caesar Augusta han sido tres: la mención explícita de la origo; la presencia de una tribu ajena a los habitantes de la ciudad, que fueron inscritos en la Aniensis; ${ }^{4}$ y la detección de determinados nomina o cognomina que pueden remitir a un horizonte no hispano. ${ }^{5}$ Conviene reseñar, no obstante, que el estudio de las dinámicas inmigratorias existentes en Caesar Augusta cuenta con importantes limitaciones derivadas del escaso número de inscripciones conservadas en la ciudad, donde muchas de ellas fueron reutilizadas en construcciones de épocas posteriores al ser esta una zona de pocas canteras.

\footnotetext{
3 Cf. Ozcáriz 2013, 55-96.

$4 \quad C f$. Wiegels 1985, 101; Fasolini, 2012, 38.

5 Sobre los mismos: Conway 1967; Kajanto 1982.
} 
Por otro lado, la detección de la emigración protagonizada por los Caesaraugustani ha sido realizada tomando como base dos indicadores: en primer lugar, la mención de la origo, que aparece expresada de diferentes formas en las inscripciones que hemos reunido pero que, en cualquier caso, indica siempre el interés de la persona que la emplea por vincularse a su patria de origen. En segundo término contamos con la presencia de la tribu Aniensis. Este indicador resulta particularmente útil en el caso de los Caesaraugustani que se desplazaron dentro de los límites de la Península Ibérica, ya que Caesar Augusta fue la única ciudad de Hispania cuyos habitantes quedaron inscritos en esta tribu. En consecuencia, si excluimos a los dos legionarios de origen galo e itálico que portan esta tribu e indican expresamente una origo extrapeninsular, ${ }^{6}$ resulta muy probable que el resto de ciudadanos pertenecientes a la tribu Aniensis que hemos documentado en las provincias hispanas tuvieran un origen o vinculación familiar con Caesar Augusta.

Teniendo en cuenta todos estos criterios hemos elaborado un corpus epigráfico compuesto por treinta y una inscripciones que conforman la base documental de nuestro trabajo. Un primer análisis de esta documentación nos ha permitido establecer la existencia de dos grandes tipos de movilidad atendiendo a la duración del desplazamiento. Así, tendríamos, por un lado, la movilidad que viene marcada por mostrar un carácter de migración, es decir, de permanencia en el lugar de destino. Este hecho la diferencia del segundo tipo de movilidad que hemos definido y que es aquella que se caracteriza por poseer un carácter temporal, dado que implicaba el retorno de sus protagonistas a su lugar de origen o bien la realización de una estancia corta en Caesar Augusta como paso previo a un segundo traslado, generalmente a la capital provincial.

La ciudad elegida para abordar este estudio, la colonia Caesar Augusta, conforma una de las fundaciones urbanas más significativas de Augusto en la Península Ibérica, como pone de manifiesto el que el emperador la bautizara con su propio nombre. ${ }^{7}$ Desde sus inicios fue concebida como una

6 Se trata de M.Cornelius, originario de Forum Iulium (AE 1993, 1036), y de Marcus Volumnius, natural de Cremona (CIL II 2631). Ambos sirvieron en las filas de la legio $X$ Gemina.

7 De forma reciente F. Beltrán (2014, 131 y 136-139) ha señalado que aunque la tradición literaria haya adoptado la variante Caesaraugusta para referirse a la ciudad, el nombre oficial de la misma se escribía separado, tal y como aparece consignado en diversos epígrafes (CIL II 6417; III 14511; VI 9; IX 793; $A E$ 1946, 200) y acuñaciones monetales (a modo de ejemplo: RPC I 304-306, 308, 311, 319, 320-321). En ellos se documenta la 
colonia de ciudadanos romanos, tal y como se observa en la obra de Plinio, ${ }^{8}$ autor que subraya también la posesión por parte de la ciudad del privilegio complementario de la immunitas (NH. III, 4, 24). Desde un punto de vista geográfico Estrabón describe la privilegiada situación de la colonia junto al río Ebro y su puente de piedra (III, 4, 10), mientras que su importancia dentro de la Hispania Citerior queda reflejada en el texto de Pomponio Mela (II, 88), que incluyó Caesar Augusta entre las clarissimae Urbes de esta provincia. La ciudad aparece asimismo mencionada en los itinerarios de época antigua, ya que conformó un punto clave en la red viaria de la región. ${ }^{9}$ A escala provincial Caesar Augusta servía como punto de enlace entre el litoral y las tierras interiores de la Citerior. Desempeñaba este papel gracias al carácter navegable del Ebro, que, según Plinio, podía remontarse hasta Vareia, la actual Varea, cerca de Logroño (NH. III, 4, 21). Con este hecho debería relacionarse el puerto fluvial con el que fue dotada la ciudad. ${ }^{10}$

En relación a la fundación de la colonia, ${ }^{11}$ aunque contamos con algunas propuestas que la vinculan con un proyecto inconcluso de César ${ }^{12}$ o con la figura de Germánico y su ejercicio como magistrado honorífico en la colonia, hecho constatado en una de las series monetales acuñadas por la ciudad ( $R P C$ I 325-329), ${ }^{13}$ no existe actualmente ninguna duda sobre la autoría augustea de la deductio. ${ }^{14}$ No obstante, a la hora de determinar una fecha concreta para este acontecimiento la historiografía se ha dividido en dos grandes grupos. Por un lado, se encuentran aquellos autores que sitúan la fundación en un horizonte

forma abreviada C C A, Colonia Caesar Augusta. La cuestión del nombre de la ciudad y su enorme carga político/simbólica fue ya observada por J. Arce $(1979,113-116)$ y ha sido abordada en diversos trabajos por F. Beltrán (1992, 31-44; 2014, 131-139).

8 En relación a las fuentes que mencionan la colonia uid. Fatás 1975-76, 113-134.

9 Cf. Roldán 1975, 226. Destaca particularmente la presencia de la ciudad en el Itinerario Antonino, donde aparece referida como Caesaraugusta $(392.1 ; 438.1 ; 439.4 ; 439.13$; 443.2; 444.2; 446.1; 446.2) y Caesarea Augusta (448.1; 451.2; 452.6). Por su parte, en el Anónimo de Rávena aparece citada como Caesaraugustam (310.3-4; 311.8-9).

10 Sobre el mismo uid. Aguarod y Erice 2003, 143-155.

11 Para un estado de la cuestión con bibliografía actualizada uid. Ortiz 2019a, 377-381.

12 Cf. Canto 1990, 296; 2001, 451.

$13 C f$. Gómez-Pantoja 1994, 169-202, con conclusiones en p. 193. Según esta propuesta, aunque la ciudad habría sido fundada en torno a los años 15-14 a.C. (p. 188), no habría obtenido el status colonial hasta una fecha indeterminada de finales del periodo augusteo (p. 193). Se basa para ello en la serie $8^{\circ}$, donde se menciona por primera vez el título colonial mediante la abreviatura C C A.

14 A modo de ejemplos: Salmon 1969, 164; Brunt 1971, 587 y 592, n 26; Galsterer 1971, 70, $\mathrm{n}^{\circ}$ 17; Sutherland 1971, 141; MacMullen 2000, 52, $\mathrm{n}^{\circ} 16$. 
cronológico similar al de Augusta Emerita, es decir, en torno al año 25 a.C. o con posterioridad al mismo, habiéndose propuesto los años 24-23 a.C. para la fundación. Los argumentos empleados para defender esta propuesta son fundamentalmente numismáticos, relacionados con los aspectos iconográficos de las acuñaciones o con el ritmo de las amonedaciones. ${ }^{15}$ Sin embargo, esta fecha tiene como principal argumento en contra el que las legiones IIII Macedonica y VI Victrix, protagonistas de la fundación junto a la X Gemina, habrían llegado a Hispania probablemente con posterioridad a esos años. ${ }^{16}$ Por ello, un segundo grupo de autores considera más apropiado retrasar la fundación hasta el bienio 15-14 a.C. apoyándose en un fragmento de Dión Casio (LIV, 23, 7) donde se describe el establecimiento por parte de Augusto de diversas colonias in Africa, Sicilia, Macedonia, utraque Hispania. Esta fecha coincidiría, además, con el segundo viaje de Augusto a Hispania, lo que permitiría llevar la fundación de Caesar Augusta hasta el año 14 a.C. ${ }^{17}$ Esta datación contaría con el respaldo de la arqueología, más en concreto con la cronología aportada por la terra sigillata itálica procedente del foro de época augustea, ${ }^{18} \mathrm{y}$ de la numismática, dado que la leyenda Augustus Divif. empleada en las primeras emisiones locales ya estaba en uso en Roma en el año 17 a.C. ${ }^{19}$

Existe, finalmente, un tercer grupo de autores que sitúa la fundación de la ciudad en torno al año 19 a.C. Esta postura, que ya fue planteada en los años 50 y 60 del siglo pasado, ${ }^{20}$ ha sido retomada de forma reciente a partir de nuevos trabajos y descubrimientos relacionados con la documentación epigráfica de la ciudad, habiéndose asignado incluso la paternidad de la fundación a M. Agripa, que habría sido el encargado de llevar a buen término la instalación de los veteranos militares. ${ }^{21}$ Igualmente, la aparición durante las excavaciones

15 Cf. Navascués 1971, 631-637; Beltrán Martínez 1976, 224-226.

16 Cf. Roldán 1974, 194-195; Rodríguez 2001, 168 y 218, nota 992.

17 Cf. Arce 1979, 27-34; Le Roux 1982a, 72-73; M. Beltrán 1990, 196; F. Beltrán 2007, 30; 2016, 303; 2017a, 533; 2017b, 161 y 170.

18 Cf. M. Beltrán 1990, 196-200; Cantos 2000, 203-240 y más en concreto, 233-235.

19 Cf. Gómez 2003, 294.

20 Cf. García y Bellido 1959, 484-485; Blázquez 1962, 97; Grant 1969, 217.

21 La posibilidad de que M. Agripa hubiese participado en la deductio de Caesar Augusta fue planteada por M. Grant $(1969,217)$, que consideró al colaborador del Princeps como el adsignator encargado de nombrar a los primeros duoviri de la colonia, Q. Lutatius y M. Fabius. De forma reciente dicha propuesta ha sido retomada a partir de una relectura de la inscripción CIL II $255^{\star}$ relativa a la construcción de los muros de la ciudad (al respecto uid. Navarro 2002, 29-56), una pieza considerada falsa por los redactores del CIL y altamente sospechosa por F. Beltrán (2007, 6; 2007-08, 1071, n. 15). 
realizadas en la Plaza de las Tenerías de un áureo de Augusto ha permitido a quienes lo han estudiado volver a proponer el bienio 19-18 a.C. como momento de fundación de la ciudad. ${ }^{22}$

\section{Caesar Augusta como centro receptor de población}

Caesar Augusta, como casi todas las grandes ciudades que vertebraron el Imperio, se configuró desde sus inicios como un importante centro receptor de población. En este proceso podemos distinguir la existencia de dos etapas diferentes atendiendo a las circunstancias históricas y a las características de quienes protagonizaron cada uno de estos momentos. Así, en primer lugar encontraríamos la fase fundacional de la colonia, caracterizada por el asentamiento de varios miles de veteranos. Estos soldados no pueden ser considerados inmigrantes en el sentido estricto del término, aunque, sin duda, su llegada a Caesar Augusta implicó la existencia de una movilidad geográfica, dado que la mayor parte de ellos fueron reclutados fuera de la Península Ibérica. Posteriormente, debe reseñarse el importante papel ejercido por Caesar Augusta como capital de un amplio conventus iuridicus. Esta circunstancia la convirtió en el punto de referencia para las élites locales de las comunidades de su entorno inmediato, que vieron en ella el espacio ideal para interactuar con el poder central y también el ámbito más cercano sobre el que proyectarse socialmente para continuar su carrera pública.

\subsection{Los primeros colonos y sus descendientes}

La nueva colonia fue establecida con el objetivo de que se convirtiera en la principal ciudad de la región desde un punto de vista viario y también administrativo. ${ }^{23}$ Asimismo, su creación fue concebida como una forma de regenerar el territorio, afectado notablemente por las guerras civiles del último siglo. ${ }^{24}$ La formalización de la deductio implicó el establecimiento en Caesar Augusta de un importante contingente de población foránea que ha sido estimado entre 2.000 y 3.000 personas. ${ }^{25}$ Estos nuevos ciudadanos, miembros principalmente de las legiones IIII Macedonica, VI Victrix y X Gemina, habrían intervenido directamente en la construcción de la ciudad, tal y como

22 Cf. Domínguez y Aguilera 2008, 455-472. Sobre la fundación de la ciudad en el año 19 $/ 18$ a.C. uid. p. 464.

23 Cf. Dopico y Santos 2016, 111-131; F. Beltrán 2017a, 534.

24 Cf. F. Beltrán 2017a, 535; 2017b, 156-159.

25 Cf. Arce 1979, 36; F. Beltrán 2016, 304-305; 2017b, 165. 
se desprende de las marcas legionarias encontradas en varios edificios del foro. ${ }^{26}$ La participación de veteranos de estas tres unidades en la fundación de Caesar Augusta se observa asimismo a través de las acuñaciones realizadas por la ceca local, donde los estandartes de estas legiones figuran en varios reversos (RPC I 311, 315, 319-321, 325-326 y 346). Por desgracia, el limitado corpus epigráfico aportado por Zaragoza no ha permitido documentar hasta el momento la presencia de estas unidades en ninguna inscripción, por lo que la información epigráfica relativa a los primeros colonos es prácticamente inexistente. No obstante, las dinámicas históricas que caracterizan el momento de su fundación nos permiten suponer, siguiendo el ejemplo de otras colonias hispanas, que la mayoría de los veteranos asentados en Caesar Augusta habrían sido reclutados en el norte de Italia o en la Gallia Narbonensis. ${ }^{27}$ Esta última procedencia ha sido planteada tradicionalmente a través de la toponimia; concretamente, la existencia a unos 40 kilómetros al oeste de la colonia de un asentamiento rural llamado Pagus Gallorum (actual Gallur) podría relacionarse con el asentamiento de colonos romanos, quizás de origen galo, en época fundacional. ${ }^{28}$ De igual modo, también pudieron haber sido integrados en la nueva civitas algunos itálicos previamente establecidos en la región, como aquellos que aparecen referidos en el Bellum Civile tras la batalla de Ilerda (BC. I, 51). El papel de estos grupos sociales en la nueva colonia debió ser dominante. Su posición contrastaría con la situación de la población indígena, cuya realidad socio-política quedó desarticulada. No obstante, es posible que a muchos de ellos se les hubiera permitido establecerse en la pertica colonial en calidad de incolae. ${ }^{29}$

A pesar de las limitaciones referidas contamos con cuatro inscripciones que arrojan interesante información sobre los momentos iniciales de la colonia. La primera de ellas fue encontrada en el casco urbano de Zaragoza, aunque actualmente se desconoce su paradero. Se trata del epitafio de Q. Vettius Amabilis, ${ }^{30}$ ciudadano romano inscrito en la tribu Tromentina que era originario de Aquae Statiellae, que debemos identificar con la actual ciudad italiana de Acqui Terme, ubicada en la fértil llanura del Po. Por desgracia, la

\footnotetext{
26 Sobre estas marcas uid. F. Beltrán 2007-08, 1069-1079, especialmente, 1073-1079.

27 Cf. F. Beltrán 2007, 6-7.

28 Cf. F. Beltrán 2006, 183-200, más en concreto, 197-198; F. Beltrán y Magallón 2007, 102; F. Beltrán 2016, 310.

$29 \mathrm{Al}$ respecto uid. F. Beltrán 2017b, 165-170.

30 CIL II 2993: Q. Vettio M.f. Ama[bili] Trom(entina) / Aqui[s St]atiellis / [h]eredes ex testamento
} 
inscripción no aporta datos sobre las causas que motivaron el desplazamiento de su protagonista; igualmente, la pérdida del epígrafe nos ha privado de poder contar con una datación concreta para el mismo. Pese a estos condicionantes, E. W. Haley planteó la posibilidad de que Q. Vettius Amabilis hubiese sido un legionario itálico, ${ }^{31}$ lo que situaría este epígrafe en una fecha bastante temprana y nos permitiría relacionarlo con la fase fundacional de Caesar Augusta. Esta hipótesis, que consideramos aceptable, se vería reforzada si tenemos en cuenta los paralelos onomásticos existentes entre este personaje y los veteranos itálicos C. Vettius (CIL II $\left.{ }^{2} / 5,1025\right)$ y L. Vettius $\left(C I L \mathrm{II}^{2} / 5,1267\right)$, asentados en Urso y Astigi en época de Augusto. La temprana fecha de sus inscripciones, su servicio como militares y su origen itálico podrían ponerse en relación con este epígrafe zaragozano de fecha indeterminada que quizás estuviese aludiendo a uno de los primeros colonos asentados en Caesar Augusta. Igualmente, conviene reseñar que uno de los primeros magistrados constatados en esta colonia portaba también en su onomástica el nomen Vettius. Se trata de C. Vet(tius) Lancia, que aparece identificado como duunviro en las acuñaciones monetales realizadas por la ceca local en los años 4-3 a.C. (RPC I 319-321).

Las tres inscripciones restantes han sido halladas lejos de Zaragoza. Sobre ellas volveremos con posterioridad (uid. apartado 3.1.2), aunque ahora consideramos oportuno realizar algunos breves comentarios. En ellas se encuentran documentados tres militares que sirvieron en las legiones X Gemina y IIII Macedonica, ambas participantes en la deductio colonial. La temprana fecha de estas inscripciones, la onomástica de sus protagonistas y el hecho de que éstos hubiesen servido en las mismas unidades con las que se fundó la ciudad, permiten plantear su consideración como descendientes de los primeros colonos cesaraugustanos. Se trata de [---] Tertius, que sirvió en la IIII Macedonica y cuya inscripción procede de Vareia (Varea, La Rioja); de $M$. Valerius Secundus, veteranus de la X Gemina documentado en Petavonium (Rosino de Vidriales, Zamora); y de L. Vissellius Niger, veterano de una unidad desconocida que falleció en el territorio de Clunia. 


\begin{tabular}{|c|c|c|c|c|c|c|c|}
\hline & Cron. & Origo & Tribu & $\begin{array}{l}\text { Lugar de } \\
\text { hallazgo }\end{array}$ & Status & $\begin{array}{c}\text { Cursus } \\
\text { honorum }\end{array}$ & Referencia \\
\hline $\begin{array}{c}\text { M. Valerius } \\
\text { Secundus }\end{array}$ & \begin{tabular}{|} 
mitad o tercer \\
cuarto del \\
s. I d.C.
\end{tabular} & & Aniensis & $\begin{array}{c}\text { Petavonium } \\
\text { (Zamora) }\end{array}$ & $\begin{array}{c}\text { civis } \\
\text { Romanus }\end{array}$ & $\begin{array}{l}\text { veteranus } \\
\text { ¿legionis } X \\
\text { Geminae? }\end{array}$ & CIL II 2630 \\
\hline $\begin{array}{l}\text { Q. Vettius } \\
\text { Amabilis }\end{array}$ & & $\begin{array}{c}\text { Aquae } \\
\text { Statiellae }\end{array}$ & Tromentina & Zaragoza & $\begin{array}{c}\text { civis } \\
\text { Romanus }\end{array}$ & & CIL II 2993 \\
\hline $\begin{array}{c}\text { L. Vissellius } \\
\text { Niger }\end{array}$ & $\begin{array}{c}\text { transición s. I } \\
\text { al II d.C. }\end{array}$ & & Aniensis & $\begin{array}{c}\text { Clunia } \\
\text { (Burgos) }\end{array}$ & $\begin{array}{c}\text { civis } \\
\text { Romanus }\end{array}$ & veteranus & $\begin{array}{l}A E 1988, \\
\quad 806\end{array}$ \\
\hline [---] Tertius & $\begin{array}{l}\text { Tiberio- } \\
\text { Nerón }\end{array}$ & & Aniensis & $\begin{array}{c}\text { Vareia } \\
\text { (La Rioja) }\end{array}$ & $\begin{array}{c}\text { civis } \\
\text { Romanus }\end{array}$ & $\begin{array}{c}\text { veteranus } \\
\text { legionis IIII } \\
\text { Macedonicae }\end{array}$ & $\begin{array}{c}A E 1990, \\
576\end{array}$ \\
\hline
\end{tabular}

Tabla 1. Posibles colonos y descendientes de colonos relacionados con la deductio de Caesar Augusta.

\subsection{Caesar Augusta y su papel como capital conventual}

El establecimiento del sistema conventual convirtió a Caesar Augusta en el principal núcleo urbano de un amplio territorio integrado por cincuenta y cinco populi (Plin., NH. III, 3, 24). Su papel como capital conventual puede ser analizado a través de algunas de las inscripciones honoríficas conservadas en el foro provincial de Tarraco. ${ }^{32}$ Gracias a ellas conocemos las trayectorias públicas de algunos notables de la región que reflejan claramente las dinámicas existentes en el Conventus Caesaraugustanus y el papel central jugado en él por su capital. Algunos de estos personajes fueron incorporados a la élite local de Caesar Augusta como paso previo a su promoción a escala provincial; otros recibieron este importante reconocimiento como culminación de su vida pública. ${ }^{33}$

A la primera de estas categorías pertenecen M. Sempronius Capito, natural de Grallia, ${ }^{34}$ y M. Valerius Capellianus, originario de Damania. ${ }^{35}$ Sus carreras públicas, que presentan notables similitudes, muestran claramente el importante papel jugado por Caesar Augusta a escala regional. ${ }^{36}$ Ambos

32 Cf. Ortiz de Urbina 2006, 46-84.

33 Cf. Andreu 2013, 77.

34 CIL II²/14, 1165: M. Sempr(onio) M. f. / Quir(ina) Capitoni / Gralliensi adlecto / in ordine Caesaraug(ustano) / omnib(us) honorib(us) / in utraq(ue) r(e)p(ublica) s(ua) f(uncto) / flam(ini) p(rovinciae) H(ispaniae) C(iterioris) / p(rovincia) H(ispania) C(iterior).

35 CIL II²/14, 1169: M. Valerio / M. fil. Gal(eria) / Aniensi / Capelliano / Damanitano adlec/to in coloniam / Caesaraugustanam / ex benefic(io) divi Hadriani / omnib(us) honorib(us) in utraq(ue) / re p(ublica) funct(o) flam(ini) Rom(ae) divor(um) et Aug(ustorum) / p(rovinciae) H(ispaniae) C(iterioris). 
personajes desempeñaron inicialmente los honores en sus respectivas comunidades de origen $y$, posteriormente, optaron por trasladarse a la capital conventual, donde fueron admitidos en el ordo local mediante la fórmula de la adlectio, una práctica muy común empleada en el mundo romano como mecanismo para robustecer las aristocracias municipales. ${ }^{37}$ Este hecho habría permitido a M. Sempronius Capito y a M. Valerius Capellianus ocupar también las magistraturas locales en Caesar Augusta, tal y como pone de manifiesto el uso en ambas inscripciones de la fórmula omnib(us) honorib(us) in utraq(ue) $r(e) p$ (ublica) s(ua) $f$ (uncto) con la que se abrevian epigráficamente los cargos públicos locales. ${ }^{38}$ En el caso de $M$. Valerius Capellianus sabemos además que su incorporación al ordo local de Caesar Augusta fue consecuencia directa de la intervención del emperador Adriano, hecho que este personaje hizo constar con orgullo en su inscripción. La trascendencia de este acontecimiento ha quedado reflejada igualmente en su onomástica, dado que a la tribu Galeria, propia de Damania, su patria natal, agregó la tribu Aniensis, propia de los ciudadanos de Caesar Augusta. Finalmente, ambos notables culminaron su vida pública trasladándose a Tarraco para desempeñar el flaminado provincial. Tras el ejercicio del mismo la asamblea de la Hispania Citerior erigió los correspondientes pedestales en su honor (CIL II ${ }^{2} / 14,1165$ y 1169).

En otras ocasiones el traslado a la capital conventual suponía la culminación de una exitosa vida pública, tal y como parece suceder en el caso de la Osicerdensis Porcia Materna, esposa del flamen provincial L. Numisius Montanus. En su caso el recorrido se produce a la inversa que en los ejemplos anteriores, pues su inscripción indica claramente que sus sacerdocios locales en Osicerda y Caesar Augusta fueron ejercidos con posterioridad (et postea) al flaminado

37 Al respecto, uid. Rodríguez Neila 1981, 15-16; Curchin 1990, 26 y 100.

38 Cf. Ortiz de Urbina 2006, 56. Para G. Fatás y M. Martín 1977, 66, no 86 la adlectio de M. Sempronius Capito se habría producido tras ejercer el flaminado provincial. Estos autores consideran que Marcus Sempronius Capito habría muerto en Tarraco, por lo que la adlectio habría tenido, además, un carácter meramente honorífico. Sin embargo, esta consideración resulta difícil de aceptar, ya que parece más lógico su traslado a la capital conventual como paso intermedio antes de emprender la carrera provincial, sobre todo teniendo en cuenta su procedencia de una comunidad pequeña y, por tanto, con escasa proyección más allá de su territorio inmediato. Por otro lado, el hallazgo de la inscripción de M. Sempronius Capito en Tarraco tampoco certificaría su muerte en esta ciudad al ser la misma un pedestal honorífico levantado como homenaje por su ejercicio del flaminado provincial, como era costumbre en Tarraco, y no como testimonio de su fallecimiento. 
provincial asumido en Tarraco $\left(C I L \mathrm{II}^{2} / 14,1182\right) .{ }^{39}$ De esta manera, es posible que el sacerdocio provincial hubiese sido empleado como un medio para regresar a su ciudad natal tras la culminación de su carrera pública, emulando así un procedimiento atestiguado entre la aristocracia senatorial. ${ }^{40}$

\begin{tabular}{|c|c|c|c|c|c|c|c|}
\hline & Cron. & Origo & Tribu & $\begin{array}{l}\text { Lugar de } \\
\text { hallazgo }\end{array}$ & Status & Cursus honorum & Ref. \\
\hline $\begin{array}{c}\text { Porcia } \\
\text { Materna }\end{array}$ & $\begin{array}{l}120-140 \\
\text { d.C. }\end{array}$ & Osicerdensis & & Tarragona & $\begin{array}{c}\text { civis } \\
\text { Romana }\end{array}$ & $\begin{array}{l}\text { [flaminica] } \\
\text { provinciae } \\
\text { Hispaniae } \\
\text { Citerioris et postea } \\
\text { Osicerdensis, } \\
\text { Caesaraugustana, } \\
\text { Tarraconensis } \\
\text { perpetua }\end{array}$ & $\begin{array}{c}\text { CIL } \\
\mathrm{II}^{2} / 14, \\
1182\end{array}$ \\
\hline $\begin{array}{c}\text { Marcus } \\
\text { Sempronius } \\
\text { Capito }\end{array}$ & $\begin{array}{l}120-180 \\
\text { d.C. }\end{array}$ & $\begin{array}{l}\text { Gralliensis. } \\
\text { Adlecto in ordine } \\
\text { Caesaraugustano }\end{array}$ & Quirina & Tarragona & $\begin{array}{c}\text { civis } \\
\text { Romanus }\end{array}$ & $\begin{array}{l}\text { omnibus honoribus } \\
\text { in utraque re } \\
\text { publica sua functus; } \\
\text { flamen Prov. Hisp. } \\
\text { Citerioris }\end{array}$ & $\begin{array}{c}\text { CIL } \\
\mathrm{II}^{2} / 14, \\
1165\end{array}$ \\
\hline $\begin{array}{c}\text { Marcus } \\
\text { Valerius } \\
\text { Capellianus }\end{array}$ & $\begin{array}{l}\text { 140-160 } \\
\text { d.C. }\end{array}$ & $\begin{array}{l}\text { Damanitanus. } \\
\text { Adlectus in } \\
\text { coloniam } \\
\text { Caesaragustanam } \\
\text { ex beneficio Divi } \\
\text { Hadriani }\end{array}$ & $\begin{array}{c}\text { Galeria } \\
y \\
\text { Aniensis }\end{array}$ & Tarragona & $\begin{array}{c}\text { civis } \\
\text { Romanus }\end{array}$ & $\begin{array}{l}\text { omnibus honoribus } \\
\text { in utraque re } \\
\text { publica functus; } \\
\text { flamen Romae } \\
\text { Divorum et } \\
\text { Augustorum Prov. } \\
\text { Hisp. Citerioris }\end{array}$ & $\begin{array}{c}\text { CIL } \\
\mathrm{II}^{2} / 14, \\
1169\end{array}$ \\
\hline
\end{tabular}

Tabla 2. Inmigrantes indocumentados en Caesar Augusta.

39 Coincidimos en este sentido con la opinión expresada, entre otros autores, por R. Étienne 1958, 172 y D. Fishwick 2002, Vol. II, 94 y 97-98. Por el contrario, J. del Hoyo 1987, 107 creía que el desarrollo de estos sacerdocios debía leerse en un sentido ascendente: partiendo desde su municipio natal, Osicerda, Porcia Marterna se habría trasladado a la capital conventual, Caesar Augusta, y finalmente, a la capital provincial, Tarraco, donde fue nombrada flaminica de la Hispania Citerior. El hecho de colocar primero el cargo de carácter provincial obedecería, según este autor, a la intención de resaltar su importancia sobre los demás. En esta misma línea se ha mostrado también Ma. C. Gregorio 2013-14, 148.

40 Cf. Andreu 2013, 78. 


\section{Dinámicas emigratorias}

Los habitantes de Caesar Augusta también se proyectaron con frecuencia lejos de su ciudad de origen. Esta movilidad tuvo lugar tanto dentro de la propia Península Ibérica, donde hemos constatado la presencia de diversos Caesaraugustani en otras ciudades de la Hispania Citerior y en varios puntos de Lusitania, como fuera de ella, ya que son también varios los cives de Caesar Augusta documentados en otras provincias del Imperio (fig. 1).

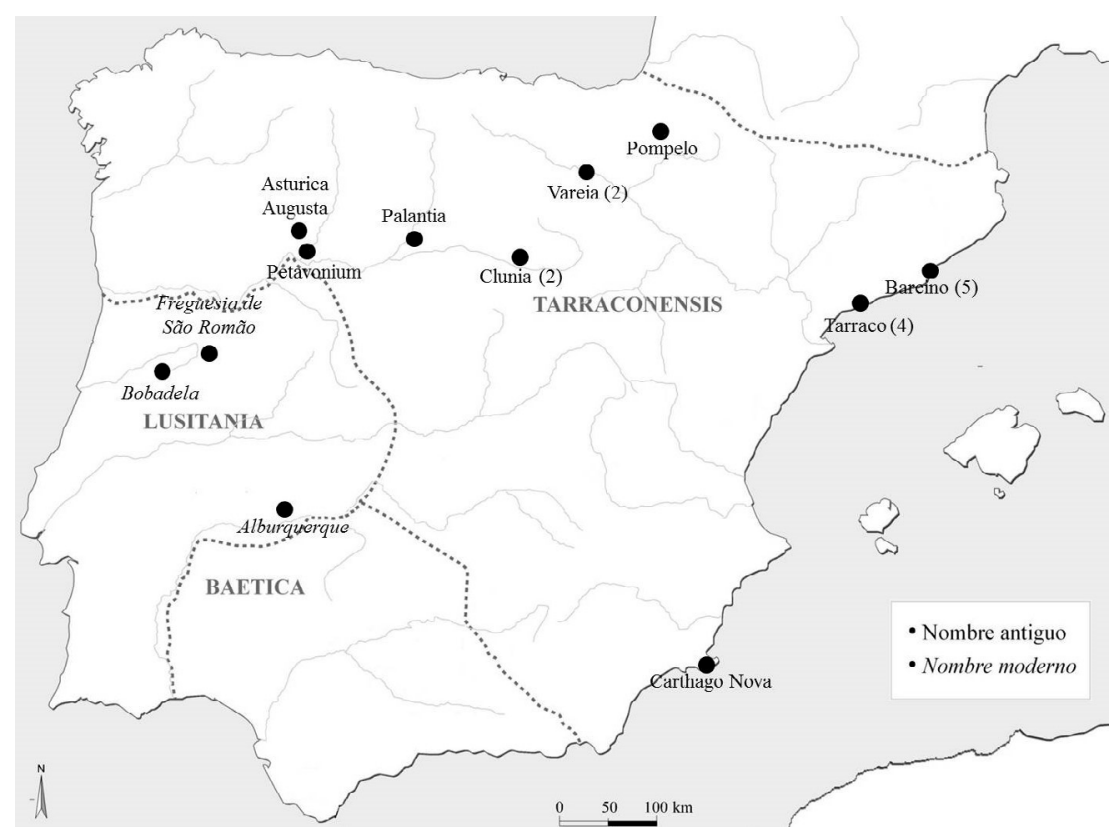

Fig. 1. Distribución geográfica de los Caesaraugustani documentados en la Península Ibérica. Entre paréntesis se indica el número de individuos encontrados en cada ciudad (elaboración propia).

\subsection{Caesaraugustani documentados en las provincias hispanas}

La mayor parte de los desplazamientos protagonizados por los Caesaraugustani tuvieron lugar en el marco de las provincias hispanas, particularmente en el interior de la enorme Hispania Citerior, de donde proceden la mayoría de las inscripciones reunidas en este apartado. Fuera de ella la presencia de naturales de Caesar Augusta se reduce notablemente, ya que tan sólo contamos con tres inscripciones procedentes de Lusitania. 


\subsubsection{Lusitania}

En esta provincia se instalaron durante el siglo II d.C.Lucius Pom(ponius?) Blastus, cuya inscripción procede de la Freguesia de São Romão (Distrito da Guarda, Portugal), ${ }^{41}$ y Caius Valerius Maxsumus, documentado en Alburquerque (Badajoz). ${ }^{42}$ La información aportada por la inscripción del primero es bastante escasa, mientras que del segundo sabemos que fue un veteranus de la legio VII Gemina fallecido a los 55 años. La cronología de su epitafio permite suponer que este personaje habría sido reclutado probablemente en época del emperador Trajano. ${ }^{43}$ Una vez finalizado su periodo de servicio $C$. Valerius Maxsumus habría optado por asentarse en la provincia de Lusitania, donde muy posiblemente contrajo matrimonio. Fruto del mismo habría sido su hija Valeria Maxsuma, que fue la encargada de dedicar la inscripción tras la muerte de su padre.

Finalmente, el tercer y último testimonio procedente de Lusitania está compuesto por la inscripción de [---] Elavius o Flavius, encontrada en el oppidum ignotum existente en Bobadela (Portugal). Se trata de una inscripción muy fragmentada que presenta importantes problemas de interpretación. Su primera editora consideró que se trataba de una dedicatoria a Roma, por lo que planteó restituir el hueco existente en la primera línea como [Rom(ae) et $],{ }^{44}$ lectura corregida posteriormente por M. Garcia, para quien estaríamos ante una dedicación en honor de Marte Augusto (RAP, 558). De forma reciente la inscripción ha sido reinterpretada por J. de Alarcão, que la ha considerado un epígrafe funerario ${ }^{45}$ levantado en memoria de un personaje del que apenas conservamos su cognomen, Elavius, quizás una mala lectura

41 AE 1992, 946: L. Pomp(onius?) Blastus / Caesaraugus/tan(us) sibi. La reconstrucción del gentilicio resulta difícil y para la misma contamos con dos posibilidades. Para A. Guerra 1990, 426-427 debería leerse el nomen Pomp(onius), lo que permite vincular a este personaje con la gens Pomponia de Caesar Augusta, cuya presencia se encuentra documentada entre los magistrados monetales de la ciudad en la figura de L. Pomponius Parra, que fue duumvir en época de Tiberio (RPC I 362-364). Sin embargo, A. P. Ramos 2004, 196, $\mathrm{n}^{\circ} 232$ se inclina por restituir el nomen Pomp(eius) argumentando que la presencia de este gentilicio resulta más frecuente en la Península Ibérica.

42 AE 1946, 200: D(is) M(anibus) s(acrum) / C. Valerius / Maxsumus Cae[s]/araugusta veter(anus) / leg(ionis) VII Geminae / Felicis ann(orum) LV / h. s. e. s. t.t. l. / Valeria Maxsu/ma patri pio / f. c.

43 Cf. Le Roux 1982a, 208; Palao 2006, 175.

44 Cf. Amaral 1982, 114.

45 Cf. Alarcão 2002-03, 166. 
de Flavius. ${ }^{46}$ Este autor restituyó también, a partir de las escasas letras restantes en la primera línea del texto, la origo Caesaraugustanus. ${ }^{47}$ Se trata de una restitución que debemos tomar con prudencia pero que, según el propio autor, se vería reforzada por el hallazgo a no mucha distancia de Bobadela de la inscripción del también cesaraugustano L. Pom(ponius?) Blastus (AE 1992, 946).

\begin{tabular}{|l|c|l|l|l|c|}
\cline { 2 - 6 } \multicolumn{1}{c|}{} & Cron. & $\begin{array}{c}\text { Lugar de } \\
\text { hallazgo }\end{array}$ & Status & $\begin{array}{c}\text { Cursushonorum / } \\
\text { Función social }\end{array}$ & Ref. \\
\hline $\begin{array}{l}\text { L.Pom(ponius?) } \\
\text { Blastus }\end{array}$ & s. II d.C. & $\begin{array}{l}\text { Freguesia de } \\
\text { São Romão } \\
\text { (Portugal) }\end{array}$ & civis Romanus & AE 1992, \\
\hline $\begin{array}{l}\text { C. Valerius } \\
\text { Maxsumus }\end{array}$ & $\begin{array}{c}\text { Mediados } \\
\text { del s. II } \\
\text { d.C. }\end{array}$ & $\begin{array}{l}\text { Alburquerque } \\
\text { (Badajoz) }\end{array}$ & civis Romanus & $\begin{array}{l}\text { veteranus } \\
\text { legionis VII } \\
\text { Geminae Felicis }\end{array}$ & $\begin{array}{c}\text { AE } 1946, \\
200\end{array}$ \\
\hline $\begin{array}{l}\text { [---] Elavius o } \\
\text { Flavius }\end{array}$ & $\begin{array}{l}\text { Bobadela } \\
\text { (Portugal) }\end{array}$ & & $\begin{array}{c}\text { Alarcão } \\
2002-03, \\
158 \text { y } 166\end{array}$ \\
\hline
\end{tabular}

Tabla 3. Caesaraugustani documentados en Lusitania.

\subsubsection{Hispania Citerior}

La mayoría de las inscripciones reunidas en este apartado proceden de la Hispania Citerior, certificando de esta forma que los habitantes de Caesar Augusta se desplazaron fundamentalmente dentro de los límites de su propia provincia. Para un mejor estudio de estos desplazamientos hemos creado dos grupos diferenciados atendiendo a la situación geográfica de las ciudades de destino y también a las características sociales de quienes protagonizaron esos desplazamientos.

\section{a) Ciudades del interior de la provincia}

Las ciudades del interior de la provincia, situadas todas ellas en el sector noroeste de la Península Ibérica, acogieron a ocho Caesaraugustani durante los siglos del Alto Imperio. Entre ellos destacan tres veterani cuyas inscripciones pueden ser relacionadas, como ya hemos referido anteriormente, con la deductio de Caesar Augusta. La más antigua de estas piezas procede de Vareia (Varea, La Rioja) y recoge el epitafio de un veteranus de onomástica incom-

\footnotetext{
46 En esta línea se muestra el comentario realizado a la inscripción en HEp 13, 977.

47 Alarcão 2002-2003, 158 y 166: ----- / [Caesar]aug(ustano) Elav[io ann(orum) --- / fili]i parenti[bus suis /ex pa]trimonio [faciendum / cura]verunt.
} 
pleta del que únicamente conocemos su cognomen, Tertius. ${ }^{48}$ Este legionario desarrolló su periodo de servicio en la IIII Macedonica, estando ya retirado en el momento de su fallecimiento. Según U. Espinosa, este monumento funerario podría datarse en una horquilla temporal comprendida entre los años 30-35 d.C. y 65-70 d.C. Se trata de una fecha flexible dado que, entre otras cosas, la edad de [---] Tertius aparece redondeada por lo menos en lustros..$^{49}$ No obstante, la presencia del término veteranus permite suponer que este legionario habría sido relevado del servicio antes del traslado de su unidad al limes germano, acontecimiento que tuvo lugar entre los años 39-43 d.C. Su servicio en la IIII Macedonica, una de las legiones que tomaron parte en la fundación de Caesar Augusta, y su pertenencia a la tribu Aniensis permiten considerar a este personaje como descendiente de uno de los colonos fundacionales, conformando de esta manera la segunda generación de Caesaraugustani, los primeros nacidos ya en la colonia. ${ }^{50} \mathrm{Su}$ presencia en Vareia debe relacionarse con las exigencias del servicio militar. Allí habría recibido la honesta missio y quizás un lote de tierras cuando su unidad partió hacia Germania.

La segunda de las inscripciones referidas procede de Petavonium (Rosino de Vidriales, Zamora). En ella fue grabado el epitafio de Marcus Valerius Secundus, ciudadano romano perteneciente a la tribu Aniensis. ${ }^{51}$ Según P. Le Roux, se trataría con casi toda probabilidad de un veteranus de la X Gemi$n a$ instalado en Rosino de Vidriales cuyo reclutamiento habría tenido lugar en época de Tiberio o Claudio, por lo que sitúa su inscripción a mediados o finales del siglo I d.C. ${ }^{52}$ No obstante, L. Hernández Guerra considera que la fecha de la misma podría adelantarse hasta los años 37-43 d.C. ${ }^{53}$ Como en el caso anterior, la cronología de la inscripción y el servicio de este personaje en una de las legiones participantes en la deductio de Caesar Augusta permiten

48 AE 1997, 912: [---]/f(ilius) Tertius v[et(eranus)] / leg(ionis) IIII Mac[ed(onicae)] / Anie(n)sis Caes[ara]/ugustanus a[nn]/orum LXX h. [s. e.] / h(eres) ex t(estamento).

49 Cf. Espinosa 1990, 11. Reitera esta misma fecha en un trabajo posterior: Espinosa y Castillo 1995-1997, 104.

50 En este sentido, su alistamiento en la IIII Macedonica, quizás la misma unidad en la que pudo haber servido su padre, sería una buena prueba de que la incorporación de los hijos al oficio militar del padre fue una de las vías seguidas por Augusto para provincializar el ejército hispano. $C f$. Espinosa 1990, 11-12; Espinosa y Castillo 1995-97, 104.

51 CIL II 2630: M. Valerius P. / f. Ani(ensi) Secundus / veter(anus) h. s.e.

$52 C f$. Le Roux 1982a, 182 y 326.

$53 C f$. Hernández 1999, 38. Esa misma fecha también es propuesta por Alonso y Crespo $2000,34, n^{\circ} 44$. 
sugerir la posibilidad de que nos encontremos ante otro descendiente de uno de los colonos fundacionales.

Finalmente, debemos señalar el caso de Lucius Vissellius Niger, ${ }^{54}$ un veteranus que habría fallecido en el territorio de Clunia entre la segunda mitad del siglo I y comienzos del siglo II d.C. La indicación de la origo y la presencia en la inscripción de la tribu Aniensis permiten confirmar su vinculación jurídica con Caesar Augusta. Igualmente interesante resulta la onomástica de este legionario. En un primer momento, su nomen fue restituido como Asellius, lectura posteriormente corregida por J. A. Abásolo, que se inclina por restituir su gentilicio como Vissellius. ${ }^{55}$ Ambos nombres presentan, en cualquier caso, una ascendencia itálica y se encuentran, además, escasamente documentados en la Península Ibérica. ${ }^{56}$ Este hecho permitiría considerar a L. Vissellius Niger como descendiente de los primeros colonos de Caesar Augusta. ${ }^{57}$ En este sentido, J. A. Abásolo planteó que este personaje podría haber servido en alguna de las unidades legionarias - IIII, VI y $X$ - que componían el ejército hispánico. ${ }^{58} \mathrm{Su}$ opinión contrasta con la de E. W. Haley, para quien la inscripción de Vissellius sería un claro ejemplo del asentamiento de veteranos en el ager Cluniensis en época de Galba, ${ }^{59}$ propuesta considerada poco viable por S. Perea. ${ }^{60}$ En nuestro caso, creemos que su presencia en Clunia debería relacionarse con las necesidades de reclutamiento existentes a finales del periodo Julio-Claudio.

Junto a estos veteranos debemos destacar también la importante trayectoria pública de [-] Memmius Barbarus. ${ }^{61}$ Su inscripción procede de Asturica Augusta, donde este personaje habría fallecido a los 59 años de edad en un periodo comprendido entre finales del siglo I y comienzos del siglo II d.C.

54 AE 1988, 806: L. Vissellius / Niger veteranus / Aniensis Caes/araugustanus / h. [s.] e. / Publia Canin[i]a / Optata Publi / Canini liberta / d. [s.f.] c.

$55 C f$. Abásolo 1994, 202. Esta lectura es confirmada en el comentario que sobre la inscripción se realiza en HEp 6, 179. No obstante, otros autores, como J. Andreu 2013, 87, emplean el nomen Asellius para referirse a este veterano.

56 Cf. Abascal 1994, 86 y 249.

57 Cf. Ortiz 2019a, 388.

58 Cf. Abásolo 1994, 202.

59 Cf. Haley 1992, 161.

60 Cf. Perea 1991, 201-202 у 206; 2001, 214.

61 CIL II 2638: [-] Memm[i]us [- f.] / Anie(n)s(i) Barbarus / sacerdos Romae et Aug(usti) / ad Lucum Aug(usti) / flamen provinciae Hispa/niae Citerio[r] is / trib(unus) mil(itum) leg(ionis) I Itali[c]ae an(norum) LVIIII h. s.e. 
Aunque no indica la origo, su pertenencia a la tribu Aniensis nos permite vincularlo con Caesar Augusta. [-] Memmius Barbarus desarrolló un importante cursus honorum en el que figura el desempeño de un sacerdotium Romae et Augusti en Lucus Augusti, del flaminado provincial en Tarraco y de un tribunado militar en la legio I Italica, responsabilidad esta última que le habría llevado a servir fuera de Hispania. ${ }^{62}$ El gran problema de la inscripción estriba en determinar si este cursus honorum se encuentra redactado de manera ascendente o descendente. ${ }^{63}$ En cualquier caso, la realidad es que [-] Memmius Barbarus falleció fuera de su ciudad de origo, lo que nos permite incluirlo entre los emigrantes de Caesar Augusta. En relación a su onomástica el cognomen Barbarus denotaría, según R. Étienne, la ascendencia nativa de este personaje. ${ }^{64}$

Igualmente interesante resulta la inscripción de L. Pompeius Primianus. ${ }^{65}$ Se trata de una tabula de hospitalidad, actualmente perdida, que fue encontrada en las cercanías de Pamplona y cuyo contenido ha llegado hasta nosotros gracias a diversos testimonios que se remontan al siglo XVI. ${ }^{66}$ En ella se recoge un hospitium firmado entre la civitas Pompelonensis y este ciudadano romano que por su pertenencia a la tribu Aniensis podemos suponer natural de Caesar Augusta.$^{67} \mathrm{La}$ inscripción puede datarse en el año 57 d.C. gracias a la referencia consular, aunque quizás la particularidad más importante que presenta el texto es la presencia del verbo renovavit, que permite suponer que

62 Sobre esta legión uid. Rodríguez 2001, 51-60.

63 Para G. Alföldy 1973, 80, el orden de desempeño de los distintos cargos sería el siguiente: tribunado militar, flaminado y sacerdotium. Difieren de esta postura otros autores como R. Étienne 1958, 136 y 193, para quien el ejercicio del flaminado provincial habría sido anterior al tribunado militar, y también F. Diego 1986, 94, n 77 , quien considera que el primer cargo ejercido por [-] Memmius Barbarus habría sido el de sacerdos Romae et Augusti, accediendo posteriormente al flaminado provincial y en último término, ya en el marco de la carrera ecuestre, al tribunado de la legio I Italica.

$64 C f$. Étienne 1958, 185.

65 CIL II 2958: Nerone Claudio Caesare / Aug(usto) Germanico II /[L.)] Caesio Martiale cos. VIII / Idus Decembris civitas Pom/pe[l]onensis hospitium renova/vit cum L. Pompeio [L.] f. Ani(ensi) / Primiano / liberis posterisq(ue) eius / egerunt leg. Se. /Pompeius Nepos [-] Sergius Cres/cens.

66 Sobre las tabulae de hospitalidad encontradas en Arre referentes a Pompelo vid. Sayas 1994, 79-115; Díaz y Guzmán 2009, 231-241. En relación a las tábulas de hospitalidad y patronato en el Imperio romano uid. Díaz y Cimarosti 2016, 319-360.

$67 C f$. Haley 1986, 260; Andreu 2013, 83. D. Fasolini plantea también la posibilidad de que se trate de un personaje de origen itálico (Fasolini 2009, 225). 
esta tabula recogería la renovación de un pacto ya existente. ${ }^{68}$ No se trata en cualquier caso del único ejemplo de esta práctica documentado en Pompelo, donde conocemos también la existencia de otro bronce, fechado en este caso en el año 185 d.C., en el que figura un pacto similar realizado entre esta ciudad y el Damanitanus P. Sempronius Taurinus (CIL II 2960). Estas iniciativas, llevadas a cabo a instancias de la élite local, permitían a la ciudad contar con un valedor en la capital conventual. ${ }^{69}$

Los tres testimonios restantes de Caesaraugustani documentados en ciudades del interior de la Hispania Citerior aportan una información bastante modesta sobre sus protagonistas. Así, en Palantia tenemos constancia de la presencia de L. Attius Proculus, que tras su muerte fue homenajeado por Attia Saturnina, a partir de cuya onomástica podemos suponer que se trataba de su hija o de su hermana. ${ }^{70}$ Por su parte, en Clunia contamos con la estela funeraria de Tulleia Araucia, que fue liberta de un personaje llamado Tulleius Philemo. ${ }^{71}$ En la misma sepultura estarían enterrados también Secundius y Celadus, fallecidos a los 18 y 5 años respectivamente, de los que se consigna su papel de servi. Es posible que nos encontremos ante una familia de libertos que tuvieron hijos antes de la celebración del matrimonio, cuando aún eran esclavos. ${ }^{72}$ La onomástica de Tulleia Araucia muestra claramente una ascendencia indígena. Tulleia es posiblemente un derivado de Tullius/Tullia, cuya extensión estuvo sin duda favorecida por la asimilación del homófono latino. ${ }^{73}$ Finalmente, en Vareia conocemos a Iulia Severina.$^{74}$ La inscripción fue erigida por su esposo, M. Iulius Atticus, seguramente un importante propietario de la zona. ${ }^{75}$ En ella la origo de la difunta se encuentra indicada mediante el empleo de la abreviatura C(olonia) C(aesar) A(ugusta), empleada en diferentes emisiones monetales y conocida también en un anillo de oro (CIL II 4976,4).

\footnotetext{
68 Cf. Díaz y Guzmán 2009, 240.

69 Cf. Díaz y Guzmán 2009, 239; Andreu 2013, 84.

70 CIL II 5764: L. Att(i)o Pro(cu)lo / Caesaraugus/tano an(norum) XXXX / Att(i)a S[at]urn/ [ina].

71 AE 1976, 357: Tulleia Araucia / Tullei Philemonis / l. Caesaraugus/tina an(norum) XXXX / [et] Secundiof. ser(vo) / an(norum) XVIII et Celadus / ser(vus) an(norum) Vh.s.s.

72 Cf. Hernández 2006, 124; 2008, 333.

73 Cf. Albertos 1966, 235-236.

74 HEp 1, 514: Iuliae Severinae / C(olonia) C(aesar) A(ugusta) ann(orum) XX / M. Iulius Att(i)cus / uxori / et sibi vivos / fecit / t(e) r(ogo) p(raeteriens) d(icas) s. t. t. l.

75 Cf. Espinosa y Castillo 1995-97, 104.
} 


\begin{tabular}{|c|c|c|c|c|c|c|c|}
\hline & Cron. & Domicilio & Tribu & $\begin{array}{l}\text { Lugar de } \\
\text { hallazgo }\end{array}$ & Status & $\begin{array}{c}\text { Cursus } \\
\text { honorum / } \\
\text { Función } \\
\text { social }\end{array}$ & Ref. \\
\hline $\begin{array}{l}\text { L. Attius } \\
\text { Proculus }\end{array}$ & s. II d.C. & Palantia & & Palencia & $\begin{array}{c}\text { civis } \\
\text { Romanus }\end{array}$ & & $\begin{array}{c}C I L \text { II } \\
5764\end{array}$ \\
\hline $\begin{array}{c}\text { Iulia } \\
\text { Severina }\end{array}$ & s. I d.C. & Vareia & & $\begin{array}{c}\text { Recajo } \\
\text { (La Rioja) }\end{array}$ & $\begin{array}{c}\text { civis } \\
\text { Romana }\end{array}$ & & $\begin{array}{c}\text { HEp 1, } \\
514\end{array}$ \\
\hline $\begin{array}{c}{[-]} \\
\text { Memmius } \\
\text { Barbarus }\end{array}$ & $\begin{array}{c}\text { transición } \\
\text { s. I al II d.C. }\end{array}$ & $\begin{array}{l}\text { Asturica } \\
\text { Augusta }\end{array}$ & Aniensis & Astorga & $\begin{array}{c}\text { eques } \\
\text { Romanus }\end{array}$ & $\begin{array}{c}\text { sacerdos } \\
\text { Romae et } \\
\text { Augusti } \\
\text { ad Lucum } \\
\text { Augusti; } \\
\text { flamen } \\
\text { Provinciae } \\
\text { Hispaniae } \\
\text { Citerioris; } \\
\text { tribunus } \\
\text { militum } \\
\text { legionis I } \\
\text { Italicae }\end{array}$ & $\begin{array}{c}C I L \text { II } \\
2638\end{array}$ \\
\hline $\begin{array}{c}\text { L. } \\
\text { Pompeius } \\
\text { Primianus }\end{array}$ & $\begin{array}{c}6 \text { de diciembre } \\
\text { del } 57 \text { d.C. }\end{array}$ & Pompelo & Aniensis & $\begin{array}{l}\text { Ezcabarte } \\
\text { (Navarra) }\end{array}$ & $\begin{array}{c}\text { civis } \\
\text { Romanus }\end{array}$ & & $\begin{array}{c}C I L \text { II } \\
2958\end{array}$ \\
\hline $\begin{array}{c}\text { Tulleia } \\
\text { Araucia }\end{array}$ & s. II d.C. & Clunia & & $\begin{array}{c}\text { Peñalba } \\
\text { de Castro } \\
\text { (Burgos) }\end{array}$ & liberta & & $\begin{array}{c}A E \\
1976 \\
357\end{array}$ \\
\hline $\begin{array}{c}\text { M. } \\
\text { Valerius } \\
\text { Secundus }\end{array}$ & $\begin{array}{l}\text { mitad o tercer } \\
\text { cuarto del } \\
\text { s. I d.C. }\end{array}$ & Petavonium & Aniensis & $\begin{array}{l}\text { Fuente } \\
\text { Encalada } \\
\text { (Zamora) }\end{array}$ & $\begin{array}{c}\text { civis } \\
\text { Romanus }\end{array}$ & $\begin{array}{l}\text { veteranus } \\
\text { ¿legionis } X \\
\text { Geminae? }\end{array}$ & $\begin{array}{c}C I L \text { II } \\
2630\end{array}$ \\
\hline $\begin{array}{c}\text { L. } \\
\text { Vissellius } \\
\text { Niger }\end{array}$ & $\begin{array}{l}\text { transición } \\
\text { s. I al II d.C. }\end{array}$ & Clunia & Aniensis & $\begin{array}{l}\text { San Juan } \\
\text { del Monte } \\
\text { (Burgos) }\end{array}$ & $\begin{array}{c}\text { civis } \\
\text { Romanus }\end{array}$ & veteranus & $\begin{array}{c}A E \\
1988 \\
806\end{array}$ \\
\hline $\begin{array}{c}\text { [---] } \\
\text { Tertius }\end{array}$ & tiberio-Nerón & Vareia & Aniensis & $\begin{array}{c}\text { Varea } \\
\text { (La Rioja) }\end{array}$ & $\begin{array}{c}\text { civis } \\
\text { Romanus }\end{array}$ & $\begin{array}{c}\text { veteranus } \\
\text { legionis IIII } \\
\text { Macedonicae }\end{array}$ & $\begin{array}{c}A E \\
1990 \\
576\end{array}$ \\
\hline
\end{tabular}

Tabla 4. Caesaraugustani documentados en las ciudades interiores de Hispania Citerior. 


\section{b) Colonias costeras}

En último término nos quedan por referir un grupo de inscripciones encontradas en las colonias de Barcino, Tarraco y Carthago Nova. La movilidad que reflejan presenta un componente social diferente al que hemos observado en el apartado anterior, ya que estuvo protagonizada por miembros de la élite cesaraugustana que buscaron mediante la misma una promoción política y que en algunos casos incluso fueron integrados en las oligarquías locales de sus ciudades de destino. Ninguno de estos personajes indica su origo, por lo que su vinculación con Caesar Augusta debe inferirse a partir de su pertenencia a la tribu Aniensis.

En el caso de Barcino contamos con cinco inscripciones. Las más antiguas, que remiten al siglo I d.C., aluden a L. Valerius Montanus ${ }^{76}$ y a L. Valerius Rufinus. ${ }^{77}$ En el caso del primero la información aportada por su inscripción resulta bastante escasa debido a la pérdida de la parte final del texto. Por el contrario, el epígrafe de L. Valerius Rufinus se conserva completo. En él este personaje aparece documentado junto a su esposa, Cornelia Homulla. Junto a ellos se encuentran Cornelius Ispanus (!) y Cornelius Marcellus, cuya filiación es la misma que presenta Cornelia Homulla, por lo que resulta probable que fuesen sus hermanos. Es posible igualmente que L. Valerius Rufinus estuviese emparentado con L. Valerius Rufus, documentado en IRC IV 126. Se da la circunstancia de que ambos Valerii realizaron enlaces matrimoniales con mujeres de la gens Cornelia. Del mismo modo, podría pensarse en alguna vinculación, difícilmente precisable, con $L$. Valerius Montanus, mencionado anteriormente, o con L. Valerius Cornelianus, que atestigua en su onomástica una clara relación entre las dos gentes mencionadas en este epígrafe (IRC IV 73). Resulta igualmente interesante señalar la presencia en Barcino de un Cornelius Sp. f. Secundus y una Cornelia Sp. f., originarios de Cartago (IRC IV 59), que presentan la misma filiación que Cornelia Homulla, la esposa de $L$. Valerius Rufinus.

Ninguno de estos dos Caesaraugustani indica el desempeño de magistraturas municipales, algo que sí conocemos en el caso de un personaje de onomástica ignota cuya pertenencia a la tribu Aniensis sugiere un origen o conexión familiar con Caesar Augusta. ${ }^{78}$ Sabemos que ejerció como edil y

76 CIL II 4590: L. Valerius / L. fi. Anie(nsi) Mo/ntanu[s ---] / ------.

77 IRC IV 221: L. Valerius L. f. An(iensi) / Rufinus sibi et / Corneliae Sp. fil. / Homullae cont(ubernali) / Cornelio Sp. f. Ispano (!) / Cornelio Sp. f. Marcello / h. m. h. n. s. n. l.s.

78 CIL II 4532: [---]o M.f. Anien(si) / [---] aed(ili) IIvir(o) / [--- M]ontana viro / [h. m. h.] n.s. 
duumvir en Barcino entre finales del siglo I y comienzos del II d.C., siendo homenajeado tras su muerte por Montana, su esposa. ${ }^{79}$ En lo que se refiere a la onomástica de este magistrado, aunque las roturas que presenta la inscripción nos impiden conocerla con certeza, la presencia en Barcino del epígrafe anteriormente mencionado de $L$. Valerius Montanu[s], inscrito también en la tribu Aniensis (CIL II 4590), llevó a S. Mariner a sugerir la existencia de un parentesco (¿padre e hijo?) entre este personaje y el protagonista del epígrafe que ahora comentamos.

Las dos inscripciones restantes localizadas en Barcino remiten al siglo II d.C. y recogen la importante trayectoria pública de C. Marius Aemilianus y de C. Iulius Seneca Licinianus. Ambos fueron homenajeados por el ordo decurionum de Barcino, lo que permite suponer que ellos o sus familias habrían sido integrados en el mismo. Al primero de estos personajes lo conocemos a través de dos inscripciones, una procedente de Iluro $^{80} \mathrm{y}$ otra de la propia Barcino ${ }^{81}$ que nos permiten reconstruir su carrera pública. Esta aparece resumida en el epígrafe hallado en Iluro a través de la conocida fórmula [o]mnib(us) honorib(us) [in r(e) p(ublica) su] a functus, mientras que en el de Barcino se detalla el ejercicio del duunvirato en tres ocasiones. Más tarde habría ocupado el cargo de flam(en) Rom(ae) et div(orum) Aug(ustorum), mediante el cual se habría encargado del culto imperial en la colonia, para, finalmente, ingresar en las decurias judiciales de Roma. ${ }^{82}$ Su pertenencia a la tribu Aniensis nos permite vincularlo con Caesar Augusta. Sin embargo, en la inscripción de Iluro C. Marius Aemilianus aparece referido como [B]arcin(onensis) immunis, lo que indicaría su incorporación entre los cives de Barcino. Este hecho pudo haberse producido de dos formas. Podemos pensar, por un lado, que su familia, originaria de Caesar Augusta, habría emigrado hasta Barcino algunas genera-

79 Cf. Curchin 1990, 183, no 428.

80 CIL II 4617: [C.] Marius L. f. / Aniens(i) / [A]emilianus / [B]arcin(onensis) immunis / [o] mnib(us) honorib(us) / [in r(e) p(ublica) su] a functus / [iudex] ex / [decuriis] quinque / [de selecti]s iud[ic(ibus)].

81 IRC IV 43: C. Mario / L. fil. An(iensi) / Aemiliano / IIvir(o) III flam(ini) / Rom(ae) et div(orum) Aug(ustorum) / iudici ex dec(uriis) V/ de selectis / Vibia Liviane / marito $\operatorname{optim}(o) /$ l.d.d.d.

82 No sabemos si este nombramiento como iudex fue origen o consecuencia de una condición ecuestre no confirmada por el ejercicio de un cargo propio de ese rango. El hecho de que únicamente se indique un cursus honorum de carácter municipal ha hecho que la mayor parte de los autores se hayan mostrado prudentes sobre el rango ecuestre de este personaje. En este sentido, uid. Rodríguez Neila 1978, 36; Caballos 1999, 488, T71; Des Boscs-Plateaux 2005, 691, no 236. 
ciones atrás. Allí habría entablado lazos con los Aemilii de esta localidad, tal y como parece desprenderse del cognomen Aemilianus portado por C. Marius. Esta alianza los habría vinculado con la élite colonial, pues la familia Aemilia aportó diversos magistrados municipales a Barcino. ${ }^{83}$ Por otro lado, tampoco sería descartable suponer que C. Marius Aemilianus hubiese sido incorporado entre los decuriones de la ciudad como consecuencia de su matrimonio con la barcinonense Vibia Liviane. ${ }^{84}$

Por su parte, C. Iulius Seneca Licinianus ${ }^{85}$ presenta igualmente una intensa carrera pública. Esta comenzó con el ejercicio de las magistraturas municipales, entre las que se consignan la edilidad, el duunvirato y el flaminado local. Posteriormente, habría servido como praefectus fabrum y como tribuno militar de las legiones VI Victrix y XV Apollinaris. A su regreso a Hispania fue designado flamen provincial, cargo que según J. M. Abascal pudo haber ejercido entre los años 92-93 d.C. y las primeras décadas del siglo II d.C. ${ }^{86} \mathrm{Al}$ término de esta función el ordo de Barcino le concedió el privilegio de colocar una estatua en el foro de la colonia. En ella el flaminado provincial fue grabado en primer lugar con el objetivo de resaltar su importancia. ${ }^{87} \mathrm{~A}$ partir del homenaje que le brinda el ordo local podemos suponer que C. Iulius Seneca Licinianus sería un civis Barcinonensis. Sin embargo, su pertenencia a la tribu Aniensis sugiere también una vinculación, bien de forma directa o a través de su familia, con Caesar Augusta. En relación a la identidad de este personaje destaca un reciente trabajo realizado por J. M. Abascal donde ha propuesto identificar a C. Iulius Seneca con el amigo del poeta Marcial, también llamado Licinianus (Ep. I, 49). ${ }^{88}$

En segundo lugar debemos comentar el numeroso grupo de inscripciones procedentes de Tarraco, donde hemos documentado seis epígrafes que

83 Serían los casos de C. Aemilius Antonianus y M. Aemilius Optatus, que desempeñaron la edilidad y el duunvirato, y de C. Aemilius, cuyo hijo fue también edil y duumvir (IRC IV, 51,52 y 58 ).

$84 C f$. Andreu 2013, 84 y 87. No se trataría del único caso documentado de este procedimiento que también conocemos a través de CIL II 4514, donde el Emeritensis L. Caecilius Optatus fue adlectus a Barc(inonensibus) inter immunes.

85 CIL II 6150: C. Iulio C. f. / An(iensi) Senecae / Liciniano / flam(ini) p(rovinciae) H(ispaniae) C(iterioris) / aed(ili) II [v]i(ro) flam(ini) / praef(ecto) fabr(um) / trib(uno) mil(itum) leg(ionis) VI / Vic(tricis) P(iae) F(idelis) et tr(ibuno) mil(itum) / leg(ionis) XV Apollin(aris) / d.d.

86 Cf. Abascal 2011, 362.

87 Cf. Crespo 2001, 267.

88 Cf. Abascal 2011, 358-364. 
remiten al siglo II d.C. Dejando a un lado los casos de M. Sempronius Capito y de $M$. Valerius Capellianus, que ya hemos comentado con anterioridad, contamos en la colonia tarraconense con cuatro homenajes dedicados por la $P$ (rovincia) H(ispania) C(iterior) en honor de otros tantos flamines provinciales cuya pertenencia a la tribu Aniensis sugiere la existencia de algún tipo de relación con Caesar Augusta. Si exceptuamos a T. Pomponius Avitus, ${ }^{89}$ cuya inscripción recoge únicamente el desempeño del flaminado provincial, el resto de notables cesaraugustanos conocidos en Tarraco desarrollaron una importante trayectoria pública que en algunos casos conllevó el ejercicio de una parte de la carrera ecuestre (uid. tabla 5). En el caso de Q. Herennius Aqui$l a^{90}$ y de $M$. Porcius Aper ${ }^{11}$ esa trayectoria pública se inició con el ejercicio de las magistraturas locales en Caesar Augusta. El primero sintetiza este hecho a través de la conocida fórmula omnib(us) honorib(us) in re p(ublica) sua functus, mientras que el segundo indica simplemente su ejercicio como duumvir. ${ }^{92}$ Con posterioridad, Q. Herennius Aquila fue incorporado a las decurias judiciales de Roma, aunque no se especifica en cuál ni bajo el mandato de qué emperador, mientras que $M$. Porcius Aper ejerció como praefectus fabrum, como tribuno militar en la legio VI Ferrata, lo que habría implicado su servicio en la región de Siria-Palestina, donde esta unidad se encontraba acantonada, ${ }^{93} \mathrm{y}$, finalmente, como procurator Augusti ab alimentis, una procuratela de rango sexagenario. En este punto la trayectoria pública de ambos personajes coincide en parte con la desarrollada por Caius $\mathrm{Cl}[\mathrm{a}]$ udius Rectus, ${ }^{94}$ que también fue praefectus fabrum y, posteriormente, procurator monetae, responsabilidad que le habría obligado a trasladarse a Roma. ${ }^{95}$ Finalmente, todos estos notables

89 CIL II 2 /14, 1158: P(rovincia) H(ispania) C(iterior) / T. Pomponio / T. f. An(iensi) Avito / flam(ini) Romae / divorum et / Augustorum / prov(inciae) Hisp(aniae) Citer(ioris).

90 CIL II $2 / 14,1143$ : [P(rovincia) H(ispania)] C(iterior) / Q. Herennio / Q. f. Aniensi / Aquilae / omnib(us) honorib(us) / in re p(ublica) sua functo / inter decurias / iudicum Romae / adlecto flamini / p(rovinciae) H(ispaniae) C(iterioris).

91 CIL II'/14, 1160: M. Porcio M. f. / Aniens(i) Apro / IIviro praefec(to) / fabr(um) trib(uno) milit(um) / leg(ionis) VI ferrat(ae) / proc(uratori) August(i) / ab alimentis / flamini p(rovinciae) H(ispaniae) C(iterioris) / p(rovincia) H(ispania) C(iterior).

92 Aunque no aparece especificado en la inscripción, nos inclinamos por pensar que ese cargo habría sido ejercido en Caesar Augusta. No obstante, H. G. Pflaum 1960-1961, 510, consideró posible que lo hubiera desempeñado en la propia Tarraco.

93 Sobre la historia de esta legión uid. Rodríguez 2001, 210-217.

$94 C I L \mathrm{II}^{2} / 14,1128$ : C. Cludio(?) Recti / f. An(iensi) Recto proc(uratori) / monetae praef(ecto) / fabr(um) flamini / provinciae His/paniae Citer(ioris) / p(rovincia) H(ispania) C(iterior).

95 En relación a la trayectoria pública de C. Cl[a]udius Rectus y al orden de ejercicio de sus cargos uid. Alföldy 1973, 68; Des Boscs-Plateaux 2005, 701, nº 250. 
culminaron sus respectivas carreras públicas con el desempeño del flaminado provincial, cargo por el que fueron honrados con el correspondiente pedestal en Tarraco.

La última inscripción que nos resta por comentar en este apartado procede de Carthago Nova y alude a M. Servilius Sulpicius Victor Crispus Considianus, ${ }^{96}$ a partir de cuyo poliónimo se ha sugerido su posible pertenencia al ordo senatorius, ${ }^{97} \mathrm{si}$ bien esta conclusión debe ser tomada con prudencia. Algo similar ocurre con su origen. Para P. Le Roux, que lo sitúa entre los senadores incerti de la Citerior, no podría descartarse que Servilius Sulpicius hubiese nacido en Carthago Nova. ${ }^{98}$ El gran problema para aceptar esta propuesta deriva su pertenencia a la tribu Aniensis, ya que los habitantes de Carthago Nova fueron inscritos en las tribus Sergia y Galeria. ${ }^{99}$ Existe la posibilidad, planteada por C. Castillo y seguida por A. Caballos, de que se tratase de un Q. Sulpicius adoptado por un M. Servilius incluido en la tribu Aniensis, algo que haría compatible la tribu con una origo local. ${ }^{100}$ De esta forma el personaje habría conservado la filiación de su padre natural (Q.f.), pero tomando el praenomen y la tribu Aniensis del adoptante, que debía proceder de Caesar Augusta o tener un origen itálico. ${ }^{101}$ Igualmente prudente se mostró E. W. Haley, quien incluyó a M. Servilius Sulpicius entre los emigrantes cesaraugustanos asentados en Carthago Nova, si bien con ciertas dudas. ${ }^{102}$

96 CIL II 3438: M. Servilio Q. f. / Ani(ensi) Sulpicio / Victo[ri] Crispo / Considiano / [---].

97 Así lo supuso Hübner (CIL II 3438), al que sigue la mayor parte de la historiografía: Le Roux 1982b, 460, no 20; Haley 1986, 361, n. 680; Castillo 1988, 240; Caballos 1990, 431; contra, F. Beltrán 2013, 644 .

$98 C f$. Le Roux 1982b, 460, $\mathrm{n}^{\circ} 20$.

99 Cf. Wiegels 1985, 103; Fasolini 2012, 41.

100 Cf. Castillo 1988, 240; Caballos 1990, 431. Esta propuesta también ha sido considerada factible por Abascal y Ramallo 1997, 196, n 51.

101 Cf. Castillo 1988, 240.

102 Cf. Haley 1986, 268, nº 534. 


\begin{tabular}{|c|c|c|c|c|c|c|c|}
\hline & Cron. & Domicilio & Tribu & $\begin{array}{l}\text { Lugar de } \\
\text { hallazgo }\end{array}$ & Status & $\begin{array}{l}\text { Cursus honorum / } \\
\text { Función social }\end{array}$ & Ref. \\
\hline $\begin{array}{l}\text { C. Cl[a]udius } \\
\text { Rectus }\end{array}$ & s. II d.C. & Tarraco & Aniensis & Tarragona & $\begin{array}{c}\text { eques } \\
\text { Romanus }\end{array}$ & $\begin{array}{l}\text { procurator monetae; } \\
\text { praefectus fabrum; } \\
\text { flamen Provinciae } \\
\text { Hispaniae Citerioris }\end{array}$ & $\begin{array}{c}C I L \mathrm{II}^{2} / 14, \\
1128\end{array}$ \\
\hline $\begin{array}{l}\text { Q. Herennius } \\
\text { Aquila }\end{array}$ & s. II d.C. & Tarraco & Aniensis & Tarragona & $\begin{array}{c}\text { civis } \\
\text { Romanus }\end{array}$ & $\begin{array}{l}\text { omnibus honoribus in } \\
\text { re publica sua functus; } \\
\text { inter decurias iudicum } \\
\text { Romae adlectus; } \\
\text { flamen Provinciae } \\
\text { Hispaniae Citerioris }\end{array}$ & $\begin{array}{c}C I L \mathrm{II}^{2} / 14, \\
1143\end{array}$ \\
\hline $\begin{array}{l}\text { C. Iulius } \\
\text { Seneca } \\
\text { Licinianus }\end{array}$ & s. II d.C. & Barcino & Aniensis & Barcelona & $\begin{array}{c}\text { eques } \\
\text { Romanus }\end{array}$ & $\begin{array}{l}\text { aedilis; duumvir; } \\
\text { flamen; praefectus } \\
\text { fabrum; } \\
\text { tribunus militum } \\
\text { legionis VI Victricis } \\
\text { Piae Fidelis; } \\
\text { tribunus militum } \\
\text { legionis XV Apollinaris; } \\
\text { flamen Provinciae } \\
\text { Hispaniae Citerioris }\end{array}$ & $\begin{array}{c}C I L \text { II } \\
6150\end{array}$ \\
\hline $\begin{array}{c}\text { C. Marius } \\
\text { Aemilianus }\end{array}$ & $\begin{array}{c}\text { 120-150 } \\
\text { d.C. }\end{array}$ & Barcino & Aniensis & Barcelona & $\begin{array}{c}\text { civis } \\
\text { Romanus }\end{array}$ & $\begin{array}{l}\text { Duumvir III; flamen } \\
\text { Romae et Divorum } \\
\text { Augustorum; } \\
\text { iudex ex quinque } \\
\text { decuriis }\end{array}$ & $\begin{array}{l}\text { IRC I 103; } \\
\text { IRC IV } 43\end{array}$ \\
\hline $\begin{array}{c}\text { T. } \\
\text { Pomponius } \\
\text { Avitus }\end{array}$ & s. II d.C. & Tarraco & Aniensis & Tarragona & $\begin{array}{c}\text { civis } \\
\text { Romanus }\end{array}$ & \begin{tabular}{|l} 
Flamen Romae \\
Divorum et \\
Augustorum Provinciae \\
Hispaniae Citerioris
\end{tabular} & $\begin{array}{c}C I L \mathrm{II}^{2} / 14, \\
1158\end{array}$ \\
\hline $\begin{array}{l}\text { M. Porcius } \\
\text { Aper }\end{array}$ & s. II d.C. & Tarraco & Aniensis & Tarragona & $\begin{array}{c}\text { eques } \\
\text { Romanus }\end{array}$ & $\begin{array}{l}\text { Duumvir; praefectus } \\
\text { fabrum; } \\
\text { tribunus militum } \\
\text { legionis VI Ferratae; } \\
\text { procurator Augusti ab } \\
\text { alimentis; } \\
\text { flamen Provinciae } \\
\text { Hispaniae Citerioris }\end{array}$ & $\begin{array}{c}\text { CIL II }{ }^{2} / 14 \\
1160\end{array}$ \\
\hline \begin{tabular}{c|} 
M. Servilius \\
Sulpicius \\
Victor \\
Crispus \\
Considianus \\
\end{tabular} & s II d.C. & $\begin{array}{l}\text { Carthago } \\
\text { Nova }\end{array}$ & Aniensis & Cartagena & ¿senator? & & $\begin{array}{c}C I L \text { II } \\
3438\end{array}$ \\
\hline $\begin{array}{l}\text { L. Valerius } \\
\text { Montanus }\end{array}$ & $\begin{array}{l}\text { Julio- } \\
\text { Claudia }\end{array}$ & Barcino & Aniensis & Barcelona & $\begin{array}{c}\text { civis } \\
\text { Romanus }\end{array}$ & & $\begin{array}{c}C I L \text { II } \\
4590 \\
\end{array}$ \\
\hline $\begin{array}{c}\text { L. Valerius } \\
\text { Rufinus }\end{array}$ & s. I d.C. & Barcino & Aniensis & Barcelona & $\begin{array}{c}\text { civis } \\
\text { Romanus }\end{array}$ & & $\begin{array}{c}\text { IRC IV } \\
221 \\
\end{array}$ \\
\hline ignotus & \begin{tabular}{|c|} 
transición \\
s. I al II \\
d.C. \\
\end{tabular} & Barcino & Aniensis & Barcelona & $\begin{array}{c}\text { civis } \\
\text { Romanus }\end{array}$ & aedilis; duumvir & $\begin{array}{c}C I L \text { II } \\
4532\end{array}$ \\
\hline
\end{tabular}

Tabla 5. Caesaraugustani documentados en las colonias litorales de la Hispania Citerior. 


\subsection{Caesaraugustani documentados en otras provincias del Imperio}

La población de Caesar Augusta también se proyectó fuera de las provincias hispanas. ${ }^{103}$ En concreto, la documentación reunida nos ha permitido constatar la presencia de seis Caesaraugustani en diversas provincias del Imperio. ${ }^{104}$ Esta movilidad tuvo como destino preferente Italia y las provincias del sector danubiano (fig. 2). Se trata de desplazamientos de naturaleza fundamentalmente militar, dado que cinco de los seis personajes estudiados señalan expresamente su servicio en el ejército. ${ }^{105} \mathrm{El} \mathrm{único} \mathrm{que} \mathrm{rompe} \mathrm{con} \mathrm{esta}$ tendencia es L. Iunius Albanus, al que tenemos documentado en una inscripción del siglo I d.C. encontrada en Luceria (Italia). ${ }^{106}$ Su procedencia no deja lugar a dudas, ya que además de indicar la origo y la tribu Aniensis, propia de los ciudadanos de Caesar Augusta, incluyó en su inscripción una referencia a la provincia Hispania Citerior similar a la que podemos encontrar en las inscripciones de otros emigrantes hispanos instalados en Italia en el mismo periodo. ${ }^{107}$ Sin embargo, resulta bastante más complicado determinar las causas que motivaron el desplazamiento de L. Iunius Albanus hasta la Regio II de Italia, dado que la información aportada por su inscripción es muy escueta. No obstante, M. Silvestrini ha planteado de forma reciente la posibilidad de que L. Iunius Albanus hubiese sido uno de los militares pertenecientes a las legiones I y VI asentados en Luceria en época de Augusto. ${ }^{108}$

El resto de personajes reunidos en este apartado desarrollaron su vida profesional en el ejército romano. Algunos sirvieron en el corazón del Imperio, como ocurrió con T. Popilius Brocchus, que estuvo enrolado en la cohors III Praetoria durante el siglo II d.C. ${ }^{109}$ Su inscripción conforma una dedica-

103 Cf. Magallón y Navarro 1991-92, 405-421.

104 Este número podría incrementarse si aceptamos el origen cesaraugustano del senador L. Funisulano Vetoniano y su hermana Funisulana Vetula, propuesto por F. Beltrán 2013, 641-652, en un reciente estudio al que remitimos para un mayor detalle.

105 Sobre los reclutamientos militares en las colonias de la Hispania Citerior uid. Ortiz 2019b.

106 CIL IX 793: L. Iunio L.f. Albano / An(iensi) Caesaraugust(a) / [ex] Hisp[a]n(ia) ci[te] $\operatorname{rior}(e)$.

107 Se trata de los Tuccitani M. Gallius Fabullus y P. Petillius Colonus, que indican su procedencia mediante una mención a su ciudad, la colonia Augusta Gemella Tucci (Martos, Jaén), y a su provincia, la Baetica, empleando para esta última las expresiones ex provincia Baetica y ex Baetica. Sobre ambos personajes uid. Ortiz 2019c, 473.

$108 C f$. Silvestrini 2008, 734, nota 63. Sobre la ciudad de Luceria uid. Keppie 1983, 164-165.

109 CIL VI 9 y 30683: Aesculapio sac(rum) / ex voto suscepto / missi honesta miss(ione) / ex coh(orte) III pr(aetoria) 7(centuria) Gradivi / Q. Rosinius Q. fil. Pol(lia) / Severus Mutina / T. Popilius T. fil. Ani(iensi) / Brocchus / Caesaraug(usta). 
toria en honor al dios Esculapio que este Caesaraugustanus realizó junto con otro personaje llamado Q. Rosinius Severus, originario de la ciudad itálica de Mutina. Este voto fue consagrado con posterioridad a la obtención de la honesta missio, lo que permite suponer que T. Popilius Brocchus habría cumplido al menos los dieciséis años de servicio estipulados por Augusto para los miembros del pretorio. ${ }^{110}$ Por tanto, es posible que nos encontremos ante un veteranus de las cohortes pretorianas que tras su retirada realizó esta dedicación como agradecimiento por haber sido licenciado con salud.

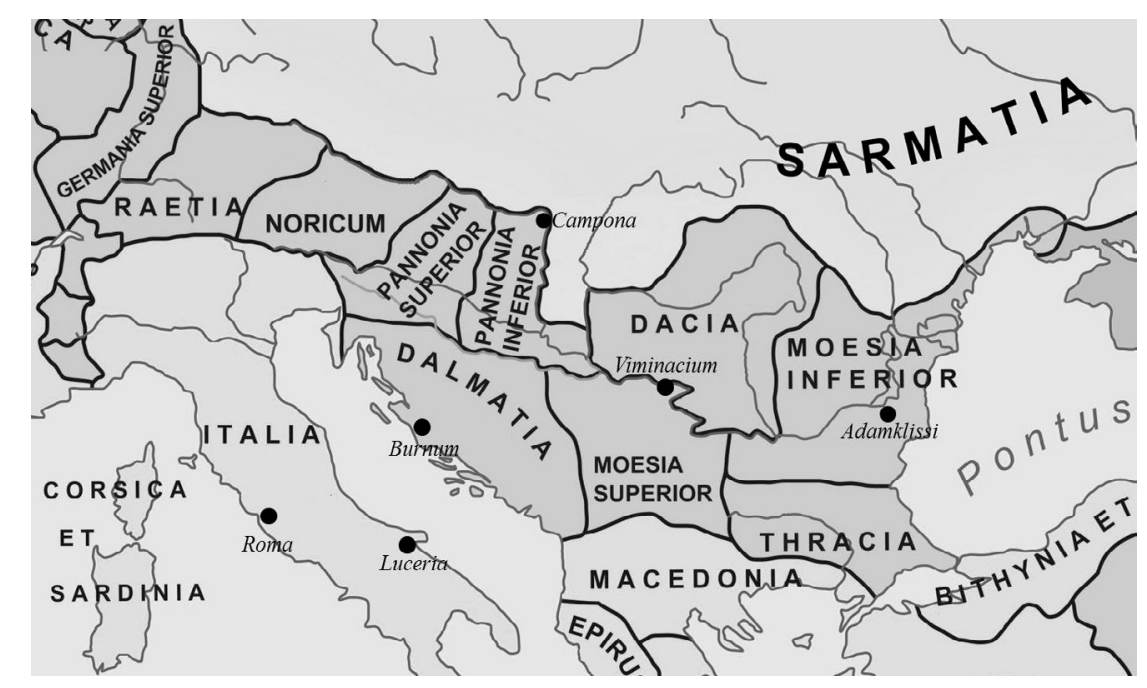

Fig. 2. Distribución geográfica de los Caesaraugustani documentados fuera de la Península Ibérica. (elaboración propia).

Los testimonios de los cuatro Caesaraugustani restantes que abordamos en este apartado provienen de las provincias danubianas del Imperio. Siguiendo el curso del Danubio hasta su desembocadura encontramos en primer lugar el territorio de Pannonia Inferior, donde ha sido localizada la inscripción de Lucius Aurelius Sequens, que remite también al siglo II d.C. ${ }^{111}$ Se trata de un veteranus de la legio II Adiutrix que tras su retirada habría optado por establecerse en la misma región donde desarrolló su servicio militar. Su unidad fue acantonada en Aquincum tras la conquista de la Dacia, por lo que la inscripción de L. Aurelius Sequens no puede ser anterior al año 106 d.C. Si a esto unimos su condición de veterano podemos suponer que este Caesarau-

110 Cf. Durry 1968, 262-264 y 290-293.

111 AE 2016, 1294: L. Aureli/us An(i)ensi \{s\} / Sequens / Caesaraug/ustae vet(eranus) / leg(ionis) II Ad(iutricis) do/nis do[nato] / [------]. 
gustanus habría sido reclutado durante la dinastía Flavia. El lugar de hallazgo de su inscripción, el campamento de Campona, estaba configurado como un asentamiento de tropas auxiliares que formaba parte de la línea defensiva del limes danubiano. Se encuentra situado a escasa distancia del campamento principal de Aquincum (Budapest), donde seguramente habría estado destinado L. Aurelius Sequens.

También en otro territorio fronterizo, en este caso la región de Moesia, contamos con otros dos testimonios relativos a milites de origen cesaraugustano cuyas inscripciones se sitúan nuevamente en el siglo II d.C. Se trata de dos militares que pudieron haber fallecido mientras se encontraban en activo, a diferencia del caso anterior. Es posible igualmente que ambos personajes hubiesen tomado parte en la conquista de la Dacia. Este hecho queda claro en el caso de Caius Vitellius Seranus, ${ }^{112}$ que aparece inscrito en el llamado Trofeo de Adamklissi (Moesia Inferior), el enorme monumento conmemorativo levantado por Trajano en el año 109 d.C. Su origo, restituida como [Ca]es(area), ha permitido plantear su origen cesaraugustano. ${ }^{113}$ Algo similar podemos sugerir para Lucius Caesius Flaccus, cuya inscripción procede de Viminacium (Moesia Superior). ${ }^{114}$ Este hispano sirvió como centurión en la legio IIII Flavia, lo que sitúa su epígrafe con posterioridad al año 86 d.C., momento en que esta unidad fue enviada a Moesia Superior. Según P. Le Roux, este personaje habría sido reclutado alrededor del año 100 d.C., lo que estaría en conexión con la cronología propuesta para su inscripción. ${ }^{115}$ Aunque la pérdida de la parte final del texto nos impide conocer datos importantes como la edad de reclutamiento o los años de servicio de este centurión, la ausencia del término veteranus permite suponer que L. Caesius Flaccus habría fallecido mientras se encontraba en activo. Merece la pena igualmente señalar la peculiar forma en que aparece escrita su origo, pues en la inscripción puede leerse Caesara Aug., en lo que, sin duda, debió ser un error del lapicida o del dedicante del epígrafe, ya que ninguno de los emigrantes originarios de Caesar Augusta conocidos hasta el momento indica así su procedencia. En cualquier caso, la

112 CIL III 14214: C. Vitellius Sera[nus Ca]es(area).

113 Cf. Roldán 1974, 434; Magallón y Navarro 1991-92, 417.

114 CIL III 14511: L. Caesius L. f. / Anie(nsi) Flaccus / Caesara Aug(usta) / 7(centurio) leg(ionis) IIII F(laviae) F(elicis) vix(it) / [a]nn(os) X[---].

115 Cf. Roldán 1974, 475, nº 727; Le Roux 1982a, 327. 
pertenencia de L. Caesius Flaccus a la tribu Aniensis reforzaría su vinculación con la colonia hispana. ${ }^{116}$

Finalmente, en Burnum (Dalmatia), campamento romano situado al norte de la actual Kistanje (Croacia), ha sido localizado el epitafio de Lucius Icconius Surio. ${ }^{117}$ Este personaje sirvió durante 23 años en la legio XI Claudia. $\mathrm{Su}$ reclutamiento pudo haber tenido lugar en época de Claudio, por lo que su edad oscilaría entre los 40 y los 50 años en el momento de su fallecimiento. ${ }^{118}$ Cronológicamente, su inscripción remite a un periodo de tiempo comprendido entre el reinado de Claudio, emperador que en el año 42 d.C. otorgó a la legio XI el epíteto Claudia, y comienzos del reinado de Vespasiano, momento en que esta unidad fue trasladada a Germania (año 70 d.C.). ${ }^{119}$ Al tratarse de una inscripción funeraria hemos de suponer que L. Icconius Surio habría fallecido con anterioridad al traslado de la legión a la frontera del Rhin.

\begin{tabular}{|c|c|c|c|c|c|c|c|}
\hline & Cron. & Domicilio & Tribu & $\begin{array}{l}\text { Lugar de } \\
\text { hallazgo }\end{array}$ & Status & $\begin{array}{c}\text { Cursus } \\
\text { honorum / } \\
\text { Función social }\end{array}$ & Ref. \\
\hline $\begin{array}{c}\text { L. } \\
\text { Aurelius } \\
\text { Sequens }\end{array}$ & $\begin{array}{l}\text { comienzos } \\
\text { del s. II } \\
\text { d.C. }\end{array}$ & Campona & Aniensis & $\begin{array}{c}\text { Nagytétény } \\
\text { (Hungría) }\end{array}$ & $\begin{array}{c}\text { civis } \\
\text { Romanus }\end{array}$ & \begin{tabular}{|l|} 
veteranus \\
legionis II \\
Adiutricis
\end{tabular} & $\begin{array}{c}A E \\
2016 \\
1294\end{array}$ \\
\hline $\begin{array}{l}\text { L. Caesius } \\
\text { Flaccus }\end{array}$ & $\begin{array}{l}\text { posterior } \\
\text { al reinado } \\
\text { de Trajano }\end{array}$ & Viminacium & Aniensis & $\begin{array}{l}\text { Kostolac } \\
\text { (Serbia) }\end{array}$ & $\begin{array}{c}\text { civis } \\
\text { Romanus }\end{array}$ & \begin{tabular}{|l|} 
centurio \\
legionis IIII \\
Flaviae
\end{tabular} & $\begin{array}{c}C I L \text { III } \\
14511\end{array}$ \\
\hline $\begin{array}{l}\text { L. Icconius } \\
\text { Surio }\end{array}$ & $\begin{array}{l}\text { mediados } \\
\text { del siglo I } \\
\text { d.C. }\end{array}$ & Burnum & Aniensis & $\begin{array}{l}\text { Kistanje } \\
\text { (Croacia) }\end{array}$ & $\begin{array}{c}\text { civis } \\
\text { Romanus }\end{array}$ & \begin{tabular}{|l|} 
miles legionis \\
XI Claudiae \\
Piae Fidelis; \\
miles \\
centuriae Titi \\
Silvani \\
\end{tabular} & $\begin{array}{c}\text { CIL III } \\
6417\end{array}$ \\
\hline $\begin{array}{l}\text { L. Iunius } \\
\text { Albanus }\end{array}$ & $\begin{array}{l}\text { comienzos } \\
\text { del s. I } \\
\text { d.C. }\end{array}$ & Luceria & Aniensis & $\begin{array}{l}\text { Lucera } \\
\text { (Italia) }\end{array}$ & $\begin{array}{c}\text { civis } \\
\text { Romanus }\end{array}$ & & $\begin{array}{c}\text { CIL IX } \\
793\end{array}$ \\
\hline $\begin{array}{l}\text { T. Popilius } \\
\text { Brocchus }\end{array}$ & $\begin{array}{l}\text { primera } \\
\text { mitad del } \\
\text { s. II d.C. }\end{array}$ & Roma & Aniensis & Roma & $\begin{array}{c}\text { civis } \\
\text { Romanus }\end{array}$ & $\begin{array}{l}\text { miles cohortis } \\
\text { III praetoriae; } \\
\text { centuriae } \\
\text { Gradivi }\end{array}$ & $C I L$ VI 9 \\
\hline $\begin{array}{c}C . \\
\text { Vitellius } \\
\text { Seranus }\end{array}$ & 109 d.C. & Adamklissi & & $\begin{array}{l}\text { Adamklisi } \\
\text { (Rumanía) }\end{array}$ & $\begin{array}{c}\text { civis } \\
\text { Romanus }\end{array}$ & miles & $\begin{array}{c}C I L \text { III } \\
14214\end{array}$ \\
\hline
\end{tabular}

Tabla 6. Caesaraugustani documentados fuera de la Península Ibérica.

$116 C f$. Wiegels 1985, 101.

117 CIL III 6417: L. Icconius L. f. / Ani(ensis) Surio Cae/saraug(usta) miles / leg(ionis) XI C(laudiae) p(iae) f(idelis) / [7(centuria)] Titi Silvani / stip(endiorum) XXIII t.f. i. / h.f.c.

118 Cf. Le Roux 1982a, 187 y 325.

119 Cf. Le Roux 1982a, 187; Rodríguez 2001, 310-311. 


\section{Conclusiones}

El proceso de conquista y urbanización de la Península Ibérica permitió el desarrollo posterior de importantes dinámicas de movilidad en las que tomaron parte grupos de población tanto de origen hispano como de extracción foránea. En la nueva realidad creada por Roma destacaron particularmente las colonias, que desde sus inicios ejercieron como centros de atracción de población. Caesar Augusta, una de las fundaciones más icónicas del periodo augusteo, formó parte de esta nueva realidad. El conjunto epigráfico que aporta la ciudad nos ha permitido constatar la existencia de diferentes dinámicas de movilidad entre sus habitantes. Dichas dinámicas están conformadas por los dos procesos tradicionales que podemos encontrar en este tipo de estudios: la inmigración y la emigración. Ambos muestran características muy diferentes en el caso de Caesar Augusta, siendo la principal de todas ellas el gran desequilibrio existente entre los inmigrantes que llegan a la colonia y los Caesaraugustani que dejan la ciudad para trasladarse a otros centros urbanos. Este claro desequilibrio nos ofrece, a primera vista, la imagen de Caesar Augusta como una ciudad esencialmente de emigrantes. Sin embargo, conviene reseñar que esta visión está en buena medida condicionada por las limitaciones que presenta la documentación epigráfica de Zaragoza, donde el número de inscripciones que se han conservado en el casco urbano de la ciudad es bastante modesto. Este hecho, consecuencia de las distintas vicisitudes históricas vividas por la ciudad, condiciona notablemente el análisis que podemos realizar sobre los fenómenos de movilidad, generando una visión que, aunque derivada de la documentación disponible, debe considerarse como parcial y, por tanto, sujeta a una futura revisión.

A pesar de estas limitaciones sabemos que la fundación de Caesar Augusta implicó el asentamiento de un importante contingente de población foránea compuesto esencialmente por veteranos pertenecientes a las legiones IIII Macedonica, VI Victrix y X Gemina. Por desgracia, la escasa documentación epigráfica de la ciudad nos ha impedido conocer hasta el momento el nombre concreto de estos veterani, cuya presencia sí ha quedado claramente reflejada en los reversos de las acuñaciones monetales realizadas por la ceca local. En cualquier caso, su actividad debió ser fundamental en las primeras fases de la colonia, como demuestran las marcas de construcción encontradas en el foro de la ciudad. Quizás podamos relacionar con este periodo la inscripción de Q. Vettius Amabilis (tabla 1), un inmigrante de origen itálico que pudo haber 
sido uno de los veteranos asentados durante la fundación. Dicha conclusión deriva de la temprana fecha de su inscripción y cuenta también con el respaldo de la onomástica, pues entre los primeros magistrados de la colonia encontramos a otro miembro de la gens Vettia ejerciendo como duumvir en el 4-3 a.C. (RPC I 319-321). Asimismo, otros dos individuos con este gentilicio fueron asentados en el mismo periodo en Urso y Astigi, dos fundaciones de marcado carácter militar. Quizás también podamos relacionar con esta primera fase de la colonia las inscripciones de tres veteranos procedentes de Vareia, Petavonium y Clunia (tabla 1). Dos de ellos, [---] Tertius y M. Valerius Secundus, aparecen sirviendo en las legiones IIII Macedonica y X Gemina, dos de las unidades que tomaron parte en la fundación de la ciudad. Este hecho, unido a la temprana fecha de sus inscripciones, datadas en la primera mitad del siglo I d.C., nos permite plantear la posibilidad de que se tratase de los descendientes de los veteranos asentados en Caesar Augusta. El tercero, L. Vissellius Niger, aunque su epígrafe remite a un momento posterior, presenta una onomástica de ascendencia itálica que también nos permite vincularlo con los momentos iniciales de la colonia, considerando que podríamos estar ante un hijo o nieto de colonos fundadores.

Con posterioridad a la fase fundacional y coincidiendo con la implantación del sistema conventual podemos observar la importante función ejercida por Caesar Augusta como núcleo vertebrador de la región gracias a su localización central en el valle del Ebro y a su privilegiada situación administrativa. De esta manera, la documentación examinada constata su papel como escala intermedia en el desarrollo de la carrera pública de algunos notables de la zona. Estos, tras completar el cursus honorum en sus ciudades de origen, generalmente pequeñas, optaron por trasladarse a la capital conventual como paso previo a su desplazamiento a la capital provincial. Este hecho se refleja claramente en las inscripciones de M. Sempronius Capito y de M. Valerius Capellianus (tabla 2). Ambos personajes se habrían trasladado a su capital conventual tras ejercer las magistraturas locales en sus respectivas comunidades de origen. Allí habrían sido incorporados al ordo de Caesar Augusta con todas las implicaciones jurídicas que ello conllevaba y, posteriormente, habrían emigrado hacia la capital de la Citerior para culminar su vida pública con el ejercicio del flaminado provincial. Sin embargo, en el caso de Porcia Materna (tabla 2) la trayectoria recorrida parece ser la contraria, dado que esta mujer, natural de Osicerda, ejerció primero como flaminica provincial y, posteriormente, fue elegida sacerdotisa en su ciudad de origen y también en Caesar Augusta. 
Frente al modesto peso documental de la inmigración, Caesar Augusta se presenta como una de las comunidades más activas desde el punto de vista de la emigración, ya que la mayor parte de las inscripciones recogidas en este trabajo aluden a Caesaraugustani documentados fuera de su ciudad de origen. Desde un punto de vista cronológico esta movilidad se concentra fundamentalmente en el siglo II d.C., tal y como podemos observar a continuación (fig. 3).

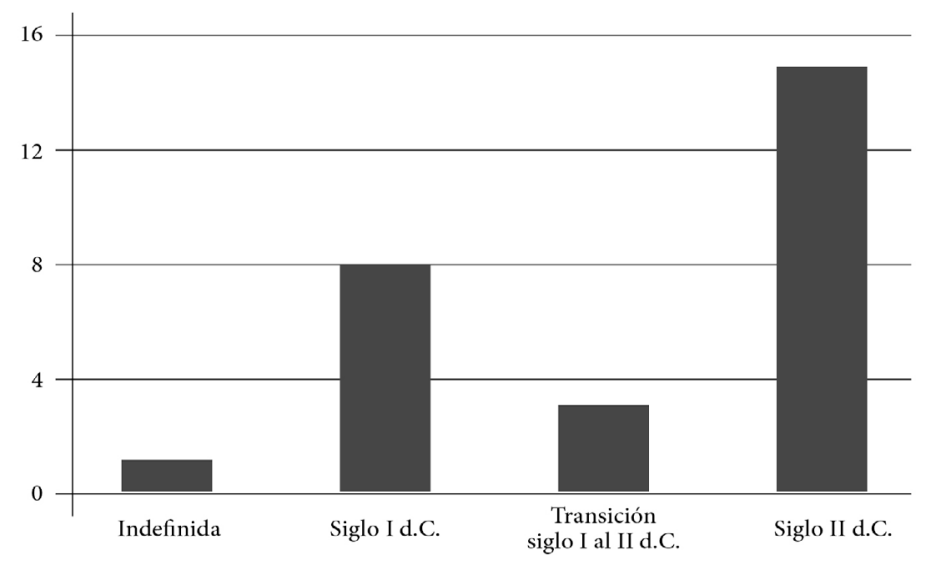

Fig. 3. Distribución cronológica de la emigración protagonizada por los Caesaraugustani.

En lo que se refiere a los centros de destino la emigración protagonizada por los Caesaraugustani puede dividirse en dos grandes bloques: por un lado encontramos las provincias hispanas, hacia donde se dirigieron la mayoría de sus habitantes; por otro, las provincias extrapeninsulares, donde contamos con una muestra menor pero igualmente interesante (fig. 4).

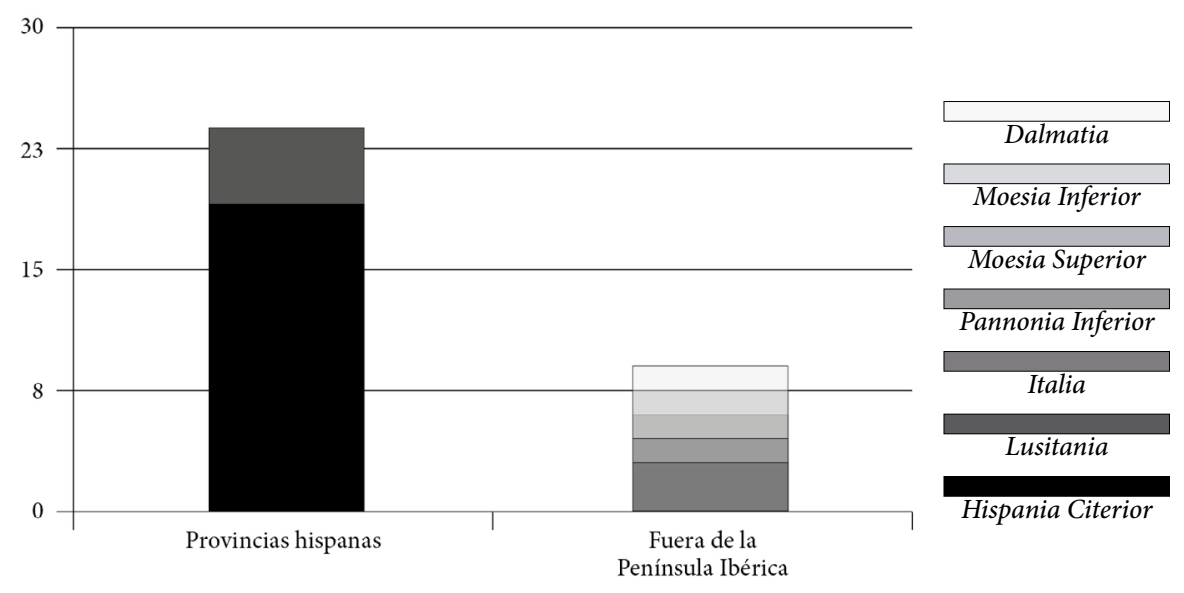

Fig. 4. Distribución geográfica de la emigración protagonizada por los Caesaraugustani. 
Finalmente, en relación a las causas de esta emigración la puesta en conjunto de la documentación epigráfica nos permite constatar la importancia del ejército y de la carrera pública. En relación al primero contamos con nueve inscripciones procedentes tanto de Hispania (4) como de fuera de ella (5). La pertenencia a este colectivo, que presenta un altísimo índice de movilidad, habría determinado el servicio de todos estos Caesaraugustani fuera de su ciudad de origen. Por su parte, el desarrollo del cursus honorum parece ser la causa que determinó la movilidad de al menos diez personajes, que son aquellos cuyas inscripciones proceden de Tarraco y Barcino (tablas 2 y 5). Junto a estos dos grupos contamos con un nutrido conjunto de inscripciones donde las causas que motivaron la movilidad de sus protagonistas no pueden ser determinadas con certeza, aunque podemos suponer, siempre en el terreno de la especulación, que tras ellas pudo subyacer una motivación económica o, simplemente, el interés por buscar nuevas oportunidades para una vida mejor en lugares más propicios.

La emigración intrapeninsular se concentra principalmente en la Hispania Citerior, donde Caesar Augusta parece mostrar una estrecha relación con Tarraco y con Barcino. Esta vinculación sería consecuencia de la cercanía geográfica entre las tres ciudades, aunque en ella también debió ser determinante el papel de Tarraco como capital provincial. Hacia ambos centros urbanos se desplazaron los miembros de algunas de las familias más prominentes de la colonia. Entre estos personajes contamos con varios caballeros que desempeñaron importantes responsabilidades en la carrera ecuestre, como podemos observar en las inscripciones de C. Cl[a]udius Rectus, praefectus fabrum y procurator monetae; de M. Porcius Aper, praefectus fabrum, tribuno militar en la VI Ferrata y procurator ab alimentis; y de C. Iulius Seneca Licinianus, que fue praefectus fabrum y tribuno militar en dos legiones diferentes. Algunos de ellos contaban con la experiencia previa desarrollada en el ejercicio de las magistraturas locales, como ocurrió con Q. Herennius Aquila, que sintetiza este honor con la conocida fórmula omnibus honoribus in re publica sua functus; con M. Porcius Aper y C. Marius Aemilianus, que fueron elegidos para ejercer el duunvirato, el segundo de ellos en tres ocasiones; y con C. Iulius Seneca Licinianus, que fue aedilis, duumvir y flamen. Todos ellos fueron designados también flamines provinciales, una responsabilidad que en muchos casos supuso la culminación de su carrera pública, como ocurrió con M. Sempronius Capito, con M. Valerius Capellianus y con T. Pomponius Avitus. También perteneció al orden ecuestre [-] Memmius Barbarus, cuya inscripción procede en 
este caso de Asturica Augusta. Este personaje, además del flaminado provincial y del tribunado militar en la legio I Italica, ejerció como sacerdos Romae et Augusti en la ciudad de Lucus Augusti.

Conviene reseñar, no obstante, que las inscripciones documentadas en Tarraco y Barcino reflejan una movilidad de naturaleza diferente. En el caso de Tarraco los epígrafes estudiados obedecen a la costumbre del concilio provincial de homenajear a los flamines salientes. A través de ellos podemos inferir la existencia de una movilidad de carácter temporal, ya que los Caesaraugustani designados para ocupar el flaminado provincial debieron desplazarse a la capital al menos durante el año que duraba el ejercicio de su cargo, pudiendo retornar a su ciudad de origen tras cesar en dicha responsabilidad. Por el contrario, en Barcino asistimos a un proceso distinto, ya que varias de las inscripciones documentadas en esta ciudad constatan la integración de sus protagonistas en la élite de la colonia, lo que habría implicado su establecimiento definitivo en ella. Este hecho quedaría reflejado en los homenajes que el ordo de Barcino dedicó a C. Iulius Seneca Licinianus y a C. Marius Aemilianus. De hecho, este último aparece específicamente mencionado como Barcinonensis inmunis, expresión que podría indicar su incorporación entre los cives de la colonia.

Junto a estas familias prominentes, cuya movilidad estuvo relacionada con el desarrollo de su cursus honorum, contamos con cuatro inscripciones que aluden a veteranos del ejército. Se trata de [---] Tertius, que sirvió en la IIII Macedonica y cuya inscripción procede de Vareia; de M. Valerius Secundus, que hizo lo propio en la $X$ Gemina y que ha sido documentado en Petavonium; de L. Vissellius Niger, que estuvo enrolado en una unidad desconocida y cuya inscripción procede de Clunia (tabla 1); y, finalmente, de C. Valerius Maxsumus, veterano de la VII Gemina documentado en Lusitania (tabla 3). Estas inscripciones de militares, a las que debemos sumar los casos documentados fuera de la Península Ibérica, como ahora veremos, constatan la continuidad del oficio militar entre los habitantes de Caesar Augusta, hecho que debemos relacionar con la naturaleza castrense de su fundación.

Finalmente, el dinamismo de la ciudad se observa también a través de otros testimonios epigráficos alusivos a Caesaragustani procedentes de otras ciudades de la Citerior como Clunia, Vareia, Pompelo o Palantia (tabla 4), y también de centros urbanos de Lusitania, donde, además de C. Valerius Maxsumus, conocemos la presencia de L. Pom(ponius?) Blastus y de [---] Elavius, 
ambos domiciliados en el norte de la provincia (tabla 3). Llama la atención, sin embargo, la inexistencia de cesaraugustanos en la Baetica.

En último término conviene reseñar la presencia de un pequeño grupo de Caesaraugustani fuera de las provincias hispanas (tabla 6). Esta movilidad, compuesta por un total de seis individuos, tiene un carácter fundamentalmente militar y está concentrada en Italia, donde contamos con el testimonio del pretoriano T. Popilius Brocchus, y sobre todo, en las provincias danubianas, de donde proceden cinco inscripciones de militares datadas durante los siglos I y II d.C. Dentro de este grupo contamos con dos veteranos, uno, L. Aurelius Sequens, que lo indica expresamente, y otro, T. Popilius Brocchus, cuya situación de veterano de las cohortes pretorianas se desprende del voto de agradecimiento que consagró a Esculapio. En lo que se refiere a los rangos únicamente constatamos a un centurión, L. Caesius Flaccus, que sirvió en la legio IIII Flavia. El resto de legionarios documentados no superaron el rango de simples milites. Completa este conjunto de Caesaraugustani documentados en el exterior Lucius Iunius Albanus, el único de todos estos personajes al que no podemos atribuir con certeza una movilidad de naturaleza militar. $\mathrm{Su}$ inscripción procede de Luceria (Italia), donde probablemente falleció a comienzos del siglo I d.C.

En relación a la distribución por sexos la documentación reunida nos permite constatar el carácter claramente masculino de la movilidad estudiada. Dentro de la misma contamos con 28 hombres, es decir, un 90,3\% de la muestra reunida, por tan sólo tres mujeres, cuyo porcentaje apenas alcanza el 9,6\% de las inscripciones recopiladas. Este desequilibrio resulta igualmente patente si desglosamos esta movilidad en función de la categoría jurídica de sus protagonistas, ya que podemos observar el amplio predominio de los ciudadanos romanos, cuyo número asciende a 29 (93,5\%), sobre el resto de grupos sociales, donde contamos únicamente con un liberto y con un personaje de situación jurídica indefinida debido al estado fragmentado de su inscripción. Igualmente, conviene señalar que dentro del grupo de ciudadanos romanos hemos identificado un importante número de caballeros, documentados principalmente en las ciudades de Tarraco y Barcino. 


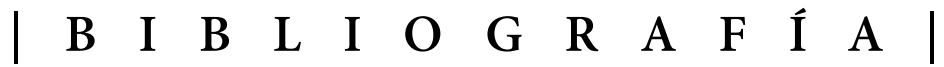

Abascal 1994: J. M. Abascal, Los nombres personales en las inscripciones latinas de Hispania, Murcia 1994.

Abascal 2011: J. M. Abascal, “Licinianus (Marcial, I 49 y 61), ¿C. Iulius Seneca Licinianus (CIL II 6150)?”, Hermes 139.3, 2011, 358-364.

Abascal y Ramallo 1997: J. M. Abascal y S. F. Ramallo, La ciudad de Carthago Nova: la documentación epigráfica, Cartagena 1997.

Abásolo 1994: J. A. Abásolo, "Sobre algunas escuelas hispanorromanas”, BSAA 60, 1994, 187-224.

Aguarod y Erice 2003: C. Aguarod y R. Erice, "El puerto de Caesaraugusta”, en: G. Pascual y J. Pérez (es.), Puertos fluviales antiguos: ciudad, desarrollo e infraestructuras, Valencia 2003, 143-155.

Alarcão 2002-03, J. de Alarcão, "A splendissima civitas de Bobadela (Lusitana)", Anas 15-16, 2002-03, 155-180.

Albertos 1996: Ma . L. Albertos, La onomástica personal primitiva de Hispania: Tarraconense y Baetica, Salamanca 1966.

Alföldy 1973: G. Alföldy, Flamines Provinciae Hispaniae Citerioris, Madrid 1973.

Alonso y Crespo 2000: A. Alonso y S. Crespo, Corpus de inscripciones romanas de la provincia de Zamora. Fuentes epigráficas para la historia social de Hispania romana, Valladolid 2000.

Amaral 1982: A. Amaral, "Sobre três inscrições perdidas da Bobadela (Oliveira do Hospital)", Conimbriga 21, 1982, 101-126.

Andreu 2008: J. Andreu, "Proyección política e imagen pública de las élites locales del Conventus Caesaraugustanus en época altoimperial a partir de la documentación epigráfica”, REA 110, 2008, 127-150.

Andreu 2013: J. Andreu, "Movilidad de personas y relaciones entre ciudades en época romana en el conventus de Caesar Augusta: aspectos epigráficos y prosopográficos", Veleia 30, 2013, 75-93.

Arce 1979: J. Arce, Caesaraugusta, ciudad romana, Zaragoza 1979.

F. Beltrán 1992: F. Beltrán, “Caesar Augusta, ciudad de Augusto”, Caesaraugusta 69, 1992, 31-44.

F. Beltrán 2006: F. Beltrán, “Galos en Hispania”, ActaArchHung 57, 2006, 183-200.

F. Beltrán 2007: F. Beltrán, "Introducción histórica”, en: F. Beltrán, (ed.), Zaragoza: colonia Caesar Augusta, Roma 2007, 3-27.

F. Beltrán 2007-08: F. Beltrán, "Marcas legionarias de la VI Victrix y la X Gemina en el foro de Caesar Augusta", Veleia 24-25, 2007-08, 1069-1080.

F. Beltrán 2013: F. Beltrán, "Una cesaraugustana en Luxor: el senador Funisulano Vetoniano y su hermana Vetula”, en: J. A. Beltrán, A. Encuentra, G. Fontana, A. I. Magallón y R. M. Marina (eds.), Otium cum dignitate. Estudios en homenaje al profesor J. J. Iso Echegoyen, Zaragoza 2013, 641-652.

F. Beltrán 2014: F. Beltrán, “Colonia Caesar Augusta. Reflexiones sobre el nombre romano de Zaragoza”, en: A. Duplá, M. V. Escribano, L. Sancho y M. A. Villacampa (eds.), Miscelánea de estudios en homenaje a G. Fatás Cabeza, Zaragoza 2014, 129-139.

F. Beltrán 2016: F. Beltrán, “Colonia Caesar Augusta: el impacto sobre el territorio y las comunidades indígenas", Revista de Historiografía 25, 2016, 301-305.

F. Beltrán 2017a: F. Beltrán, “Augusto y el valle medio del Ebro”, Gerión 35, 2017, 525-540. 
F. Beltrán 2017b: F. Beltrán, "War, destruction, and regeneration in the middle Ebro valley ( $1^{\text {st }}$ century BCE): The foundation of the colonia Caesar Augusta and its irrigation programmes", en: S. von Reden (ed.), Resources, Environment, Exchange and Power in Classical Antiquity, Vandoeuvres 2017, 151-186.

F. Beltrán y Magallón 2007: F. Beltrán y Mª. A. Magallón, “El territorio”, en: F. Beltrán, (ed.), Zaragoza: colonia Caesar Augusta, Roma 2007, 97-107.

M. Beltrán 1990: M. Beltrán, "El valle medio del Ebro y su monumentalización en época republicana y augustea (Antecedentes, Lepida-Celsa y Caesaraugusta)", en: W. Trillmich y P. Zanker (eds.), Stadtbild und ideologie. Die Monumentalisierung hispanischer Städte zwischen Republik und Kaiserzeit, Madrid 1990, 179-206.

Beltrán Martínez 1976: A. Beltrán Martínez, “Caesaraugusta”, en: Symposion de Ciudades Augusteas I. Bimilenario de la Colonia Caesaraugusta, Zaragoza 1976, 219-261.

Blázquez 1962: J. M. Blázquez, "Estado de la romanización en Hispania bajo César y Augusto", Emerita 30, 1962, 71-129.

Boscs-Plateaux 2005: F. des. Boscs-Plateaux, Un parti hispanique à Rome? Ascension des élites hispaniques et pouvoir politique d'Auguste à Hadrien (27 av. J.C.-138 ap. J.C.), Madrid 2005.

Brunt 1971: P. A. Brunt, Italian Manpower (225 B.C.-A.D. 14), Oxford 1971.

Caballos 1990: A. Caballos, Los senadores hispanorromanos y la romanización de Hispania (Siglos I-III). Prosopografía, Écija 1990.

Caballos 1999: A. Caballos, "Los caballeros romanos originarios de las provincias de Hispania. Un avance”, en: S. Demougin, H. Devijver y M. T. Raepsaet-Charlier (eds.), L'Ordre Équestre. Histoire d'une Aristocratie (II siècle av. J.C.-III siècle ap. J.C.), Roma 1999, 463-512.

Caballos y Demougin 2006: A. Caballos y S. Demougin (eds.), Migrare. La formation des élites dans l'Hispanie romaine, Burdeos 2006.

Canto 1990: A. Canto, "Las tres fundaciones de Augusta Emerita", en: W. Trillmich y P. Zanker (eds.), Stadtbild und ideologie. Die Monumentalisierung hispanischer Städte zwischen Republik und Kaiserzeit, Madrid 1990, 289-298.

Canto 2001: A. Canto, "Sinoicismo y stolati en Emerita, Caesaraugusta y Pax: una relectura de Estrabón III, 2, 15”, Gerión 19, 2001, 425-476.

Cantos 2000: A. Cantos, "La terra sigillata del Foro de Caesaraugusta (Zaragoza)", Salduie 1, 2000, 203-240.

Castillo 1988: C. Castillo, "La tribu Galeria en Hispania: ciudades y ciudadanos", en: J. González y J. Arce (eds.), Estudios sobre la tabula Siariensis, Madrid 1988, 233-243.

Conway 1967: R. S. Conway, The italic dialects, Cambridge 1967.

Crespo 2001: S. Crespo, "Los portadores del onomástico Seneca en Hispania romana”, HispAnt 25, 2001, 251-278.

Curchin 1990: L. A. Curchin, The Local Magistrates of Roman Spain, Toronto 1990.

Díaz y Cimarosti 2016: B. Díaz Ariño y E. Cimarosti, "Las tábulas de hospitalidad de Arre (Pamplona)", Chiron 46, 2016, 319-360.

Díaz y Guzmán 2009: B. Díaz Ariño y A. Guzmán Almagro, "Las tábulas de hospitalidad de Arre (Pamplona)", en: J. Andreu (ed.), Los vascones de las fuentes antiguas. En torno a una etnia de la Antigüedad Peninsular, Barcelona 2009, 231-241. 
Diego 1986: F. Diego, Inscripciones romanas de la provincia de León, León 1986.

De Ligt y Tacoma (eds.) 2016: L. De Ligt y L. E. Tacoma (eds.), Migration and Mobility in the Early Roman Empire, Leiden-Boston 2016.

Domínguez y Aguilera 2008: Ma. A. Domínguez y A. Aguilera, “Caesar Augusta a la luz de los últimos descubrimientos. Consideraciones en torno al áureo de Mars Ultor", en: A. Arévalo (ed.), Actas del XIII Congreso Nacional de Numismática. Moneda y Arqueología, Madrid-Cádiz 2008, 455-472.

Dopico y Santos 2016: M. D. Dopico y J. Santos, "La creación de la red de ciudades del poder en la Hispania Citerior", Revista de Historiografía 25, 2016, 111-131.

Durry 1968: M. Durry, Les Cohortes Prétoriennes, París 1968.

Espinosa 1990: U. Espinosa, Vareia. Enclave romano en el Valle del Ebro, Logroño 1990.

Espinosa y Castillo, 1995-97: U. Espinosa y Ma. J. Castillo, "Novedades epigráficas en el medio Ebro (La Rioja)”, Lucentum 14-16, 1995-97, 101-112.

Étienne 1954: R. Étienne, Le Culte Impérial dans la Péninsule Ibérique d’Auguste a Dioclétien, París 1958 [1972²].

Fasolini 2009: D. Fasolini, "La compresenza di tribù nelle città dela Penisola Iberica: il caso della Tarraconensis, en: J. F. Rodríguez Neila (ed.), Hispania y la epigrafía romana. Cuatro perspectivas, Faenza 2009, 179-238.

Fasolini 2012: D. Fasolini, Le tribu romane della Hispania Tarraconensis. Lascrizione tribale dei cittadini romani nelle testimonianze epigrafiche, Milán 2012.

Fatás 1975-76: G. Fatás, "Fuentes para el estudio de la Colonia Caesar Augusta”, Caesaraugusta, 39-40, 1975-76, 113-134.

Fatás y Martín 1977: G. Fatás y M. A. Martín, Epigrafía romana de Zaragoza y su provincia, Zaragoza 1977.

Fishwick 2002: D. Fishwick, The Imperial Cult in the Latin West: Studies in the Ruler Cult of the Western Provinces of the Roman Empire, Leiden 1987-2005.

Galsterer 1971: H. Galsterer, Untersuchungen zum Römischen städtewesen auf der iberischen Halbinsel, Berlín 1971.

García 1991: Mª. R. García Martínez, "Caracteres y significación socio-económica de los movimientos de población hispana hacia las provincias imperiales en época romana", HispAnt 15, 1991, 263-302.

García 1994a: Ma. R. García Martínez, "Desplazamientos de habitantes de la Bética hacia el Imperio en época romana”, en: Actas del II Congreso de Historia de Andalucía, Córdoba 1994, 383-390.

García 1994b: Ma . R. García Martínez, "Contribución de la provincia Lusitania al movimiento de población hispana hacia las provincias imperiales en época romana”, en: S. Ordóñez y P. Sáez (eds.), Homenaje al profesor Presedo, Sevilla 1994, 457-462.

García y Bellido 1959: A. García y Bellido, "Las colonias romanas de Hispania", Anuario de historia del Derecho Español 29, 1959, 447-512.

Gómez 2003: M. Gómez, "El papel de la colonia de Caesaraugusta en el contexto imperial augústeo: el testimonio histórico de la numismática", AEspA 76, 2003, 291-307.

Gómez-Pantoja 1994: J. Gómez-Pantoja, “Germánico y Caesaraugusta”, Polis 6, 1994, 169-202.

Grant 1969: M. Grant, From Imperium to Auctoritas. A Historical Study of the Aes Coinage in Roma Empire. 49 B.C.-A.D. 14, Cambridge, 1969.

Gregorio 2013-14: Ma. C. Gregorio, "Flaminicae sive sacerdotes de la Provincia Hispania Citerior: el sacerdocio femenino del culto imperial”, HispAnt 37-38, 2013-14, 137-163. 
Guerra 1990: A. Guerra, "Uma importante epígrafe proveniente do Cabeço do Crasto (S. Romao, Seia)", en: Actas do I Colóquio Arqueológico de Viseu, Viseu 1990, 425-430.

Haley 1986: E. W. Haley, Foreigners in Roman Imperial Spain: investigations of geographical mobility in the spanish provinces of the Roman Empire (30 B.C.-A.D. 284), Nueva York 1986.

Haley 1991: E. W. Haley, Migration and economy in Roman Imperial Spain, Barcelona 1991.

Haley 1992: E. W. Haley, “Clunia, Galba and the Events of 68-69”, ZPE 91, 1992, 159-164.

Hernández 1999: L. Hernández Guerra, Epigrafía romana de unidades militares relacionadas con Petavonium (Rosino de Vidirales, Zamora). Estudio social, religioso y prosopográfico, Valladolid 1999.

Hernández 2006: L. Hernández Guerra, "Las libertas en Hispania. Manifestaciones epigráficas en la provincia tarraconense”, HispAnt 30, 2006, 119-142.

Hernández 2008: L. Hernández Guerra, "La liberta en Hispanie. Manifestations épigraphiques de la province tarraconense", en: A. Gonzales (ed.), La fin du statut servile? Affranchissement, libération, abolition, vol. II, Besançon 2008, 329-359.

Hoyo 1987: J. del Hoyo Calleja, La importancia de la mujer hispanorromana en la Tarraconense y Lusitania a la luz de los documentos epigráficos, Madrid 1987.

Iglesias y Ruiz 2011: J. M. Iglesias Gil y A. Ruiz Gutiérrez (eds.), Viajes y cambios de residencia en el mundo romano, Santander 2011.

Kajanto 1982: I. Kajanto, The Latin cognomina, Roma 1982.

Keppie 1983: L. Keppie, Colonisation and veteran settlement in Italy. 47-14 B.C., Roma 1983.

Le Roux 1982a: P. Le Roux, Larmée romaine et l'organisation des provinces iberiques d'Auguste a l'invasion de 409, París 1982.

Le Roux 1982b: P. Le Roux, "Les sénateurs originaires de la province d'Hispania Citerior au Haut-Empire romain”, en: M. L. Caldelli y G. L. Gregori (eds.), Epigrafa e ordine senatorio, Roma 1982, 439-464.

MacMullen 2000: R. MacMullen, Romanization in the time of Augustus, Yale 2000.

Magallón y Navarro 1991-92: Ma . A. Magallón y M. Navarro, "Los desplazamientos humanos en el Conventus Caesaraugustanus según la epigrafía”, Zephyrus 44-45, 1991-92, 405-421.

Marín 1988: Ma. A. Marín, Emigración, colonización y municipalización en la Hispania republicana, Granada 1988.

Marco, Pina y Remesal 2004: F. Marco, F. Pina y J. Remesal (eds.), Vivir en tierra extraña. Emigración e integración cultural en el mundo antiguo., Barcelona 2004.

Navarro 2002: M. Navarro, "Agrippa et Caesaraugusta: relecture", Epigraphica 64, 2002, 29-56.

Navascués 1971: J. M. Navascués, “Cronología monetaria caesaraugustana (s. I a.C.)", BRAH $168,1971,631-637$.

Ortiz 2017: J. Ortiz Córdoba, "Reclutamiento y unidades militares en las colonias de la Hispania Meridional”, FlorIl 28, 2017, 135-158.

Ortiz 2018: J. Ortiz Córdoba, "Reclutamiento y unidades militares en las colonias romanas de Lusitania”, StHist 36, 2018, 83-116.

Ortiz 2019a: J. Ortiz Córdoba, Las colonias romanas de Hispania y los movimientos de población. Granada, Universidad de Granada. Tesis Doctoral, 2019.

Ortiz 2019b: J. Ortiz Córdoba, "Reclutamiento y unidades militares en las colonias romanas de la Hispania Citerior", Gladius 39, 2019, 71-91.

Ortiz 2019c: J. Ortiz Córdoba, "Contribución de las colonias de la Bética al proceso emigratorio hispano hacia las provincias del Imperio (siglos I-II d.C.)”, El Futuro del Pasado 10, 2019, 459-488. 
Ortiz de Urbina 2006: E. Ortiz de Urbina, "La exaltación de la elite provincial. Los homenajes estatuarios decretados o autorizados por la provincia Hispania Citerior", Epigraphica 68, 2006, 46-84.

Ozcáriz 2013: P. Ozcáriz, La administración de la Hispania citerior durante el Alto Imperio, Barcelona 2013.

Palao 2006: J. J. Palao, Legio VII Gemina (Pia) Felix. Estudio de una legión romana, Salamanca 2006.

Perea 1991: S. Perea, "Notas sobre la epigrafía militar en Clunia”, HispAnt 15, 1991, 193-206.

Perea 2001: S. Perea, "Militares clunienses fuera de Hispania en los ejércitos de los Julio-Claudios y los Flavios", en: L. Hernández, L. Sagredo y J. M. Solana (eds.), Actas del I Congreso Internacional de Historia Antigua. La Península Ibérica hace 2000 años, Valladolid 2001, 229-234.

Pflaum 1960-61: H. G. Pflaum, Les carrières procuratoriennes équestres sous le Haut-Empire Romain, III vols., París 1960-61.

Ramos 2004: A. P. Ramos, Epigrafia funerária romana da Beira Interior. Inovação ou continuidade?, Lisboa 2004.

Ricci 1992: C. Ricci, “Hispani a Roma”, Gerión 10, 1992, 103-143.

Rodríguez 2001: J. Rodríguez González, Historia de las legiones romanas, Madrid 2001.

Rodríguez Neila 1978: J. F. Rodríguez Neila, "Los jueces de las cinco decurias oriundos de la Hispania romana. Una contribución prosopográfica”, HispAnt 8, 1978, 17-66.

Rodríguez Neila 1981: J. F. Rodríguez Neila, Sociedad y administración local en la Bética romana, Córdoba 1981.

Roldán 1974: J. M. Roldán, Hispania y el ejército romano, Salamanca 1974.

Roldán 1975: J. M. Roldán, Itineraria Hispana. Fuentes antiguas para el estudio de las vías romanas en la Península Ibérica, Madrid 1975.

Sayas 1994: J. J. Sayas, "Los pactos de hospitalidad de Pompaelo en el contexto de los pactos en la Península Ibérica”, en: Los vascos en la antigüedad, Madrid 1994, 79-115.

Salmon 1969: E. T. Salmon, Roman Colonization under the Republic, Londres 1969.

Silvestrini 2008: M. Silvestrini, "Una nuova dedica imperiale della colonia di Benevento", en: M. L. Caldelli, G. L. Gregori y S. Orlandi (eds.), Epigrafia 2006. Atti della XIV Rencontre sur l'épigraphie in onore di Silvio Panciera, vol. II, Roma 2008, 725-739.

Wiegels 1985: R. Wiegels, Die Tribusinschriften des romischen Hispanien, Berlín 1985. 